University of Nebraska - Lincoln

DigitalCommons@University of Nebraska - Lincoln

\title{
Global products of vegetation leaf area and fraction absorbed PAR from year one of MODIS data
}

\author{
R. B. Myneni \\ Boston University \\ S. Hoffman \\ Boston University \\ Y. Knyazikhin \\ Boston University \\ J. L. Privette \\ NASA Goddard Space Flight Center \\ J. Glassy \\ University of Montana \\ See next page for additional authors
}

Follow this and additional works at: https://digitalcommons.unl.edu/nasapub

Part of the Physical Sciences and Mathematics Commons

Myneni, R. B.; Hoffman, S.; Knyazikhin, Y.; Privette, J. L.; Glassy, J.; Tian, Y.; Wang, Y.; Song, X.; Zhang, Y.; Smith, G. R.; Lotsch, A.; Friedl, M.; Morisette, J. T.; Votava, P.; Nemani, R. R.; and Running, S. W., "Global products of vegetation leaf area and fraction absorbed PAR from year one of MODIS data" (2002). NASA Publications. 39.

https://digitalcommons.unl.edu/nasapub/39

This Article is brought to you for free and open access by the National Aeronautics and Space Administration at DigitalCommons@University of Nebraska - Lincoln. It has been accepted for inclusion in NASA Publications by an authorized administrator of DigitalCommons@University of Nebraska - Lincoln. 


\section{Authors}

R. B. Myneni, S. Hoffman, Y. Knyazikhin, J. L. Privette, J. Glassy, Y. Tian, Y. Wang, X. Song, Y. Zhang, G. R. Smith, A. Lotsch, M. Friedl, J. T. Morisette, P. Votava, R. R. Nemani, and S. W. Running 


\title{
Global products of vegetation leaf area and fraction absorbed PAR from year one of MODIS data
}

\author{
R.B. Myneni ${ }^{\text {a,* }}$, S. Hoffman ${ }^{\text {a }}$, Y. Knyazikhin ${ }^{\text {a }}$, J.L. Privette ${ }^{\text {b }}$, J. Glassy $^{\text {c }}$, Y. Tian ${ }^{\text {a }}$, \\ Y. Wang ${ }^{a}$, X. Song ${ }^{a}$, Y. Zhang ${ }^{a}$, G.R. Smith ${ }^{a}$, A. Lotsch ${ }^{\mathrm{a}}$, M. Friedl ${ }^{\mathrm{a}}$, J.T. Morisette ${ }^{\mathrm{b}}$, \\ P. Votava ${ }^{\mathrm{c}}$, R.R. Nemani ${ }^{\mathrm{c}}$, S.W. Running ${ }^{\mathrm{c}}$ \\ ${ }^{a}$ Department of Geography, Boston University, 675 Commonwealth Avenue, Boston, MA, 02215, USA \\ ${ }^{\mathrm{b}}$ Biospheric Sciences Branch, NASA Goddard Space Flight Center, Greenbelt, MD, 20771, USA \\ ${ }^{\mathrm{c}}$ School of Forestry, University of Montana, Missoula, MT, USA
}

Received 6 April 2001; received in revised form 16 January 2002; accepted 18 February 2002

\begin{abstract}
An algorithm based on the physics of radiative transfer in vegetation canopies for the retrieval of vegetation green leaf area index (LAI) and fraction of absorbed photosynthetically active radiation (FPAR) from surface reflectances was developed and implemented for operational processing prior to the launch of the moderate resolution imaging spectroradiometer (MODIS) aboard the TERRA platform in December of 1999. The performance of the algorithm has been extensively tested in prototyping activities prior to operational production. Considerable attention was paid to characterizing the quality of the product and this information is available to the users as quality assessment (QA) accompanying the product. The MODIS LAI/FPAR product has been operationally produced from day one of science data processing from MODIS and is available free of charge to the users from the Earth Resources Observation System (EROS) Data Center Distributed Active Archive Center. Current and planned validation activities are aimed at evaluating the product at several field sites representative of the six structural biomes. Example results illustrating the physics and performance of the algorithm are presented together with initial QA and validation results. Potential users of the product are advised of the provisional nature of the product in view of changes to calibration, geolocation, cloud screening, atmospheric correction and ongoing validation activities.
\end{abstract}

(C) 2002 Published by Elsevier Science Inc.

\section{Introduction}

Leaf area index (LAI) and fraction of photosynthetically active radiation $(0.4-0.7 \mu \mathrm{m})$ absorbed by vegetation (FPAR) characterize vegetation canopy functioning and energy absorption capacity. LAI is defined as one sided green leaf area per unit ground area in broadleaf canopies and as the projected needle leaf area in coniferous canopies. LAI and FPAR are key parameters in most ecosystem productivity models and global models of climate, hydrology, biogeochemistry and ecology (Sellers et al., 1997). For effective use in large-scale models, these variables must be collected over a long period of time and should represent every region of the terrestrial surface. Satellite remote

\footnotetext{
* Corresponding author. Tel.: +1-617-353-5742; fax: +1-617-353-8399.

E-mail address: rmyneni@crsa.bu.edu (R.B. Myneni).
}

sensing is the most effective means of collecting such global fields on a regular basis. Advances in remote sensing technology (Deschamps et al., 1994; Diner et al., 1999; Justice et al., 1998) and radiative transfer modeling (Myneni and Ross, 1991; Ross, Knyazikhin, Marshak, \& Nilson, 1992) have improved the possibility of accurate estimation of these parameters from spectral and angular dimensions of remotely sensed data. The launch of TERRA with moderate resolution imaging spectroradiometer (MODIS) and multiangle imaging spectroradiometer (MISR) instruments onboard began a new era in remote sensing of the Earth system. In contrast to previous single-angle and few-channel instruments, MODIS and MISR together allow for rich spectral and angular sampling of the reflected radiation field. This sets new demands on retrieval techniques for geophysical parameters in order to take full advantage of these instruments. In this context, we have developed a synergistic algorithm for the extraction of LAI and FPAR from MODIS- and MISR-measured canopy reflectance data, 


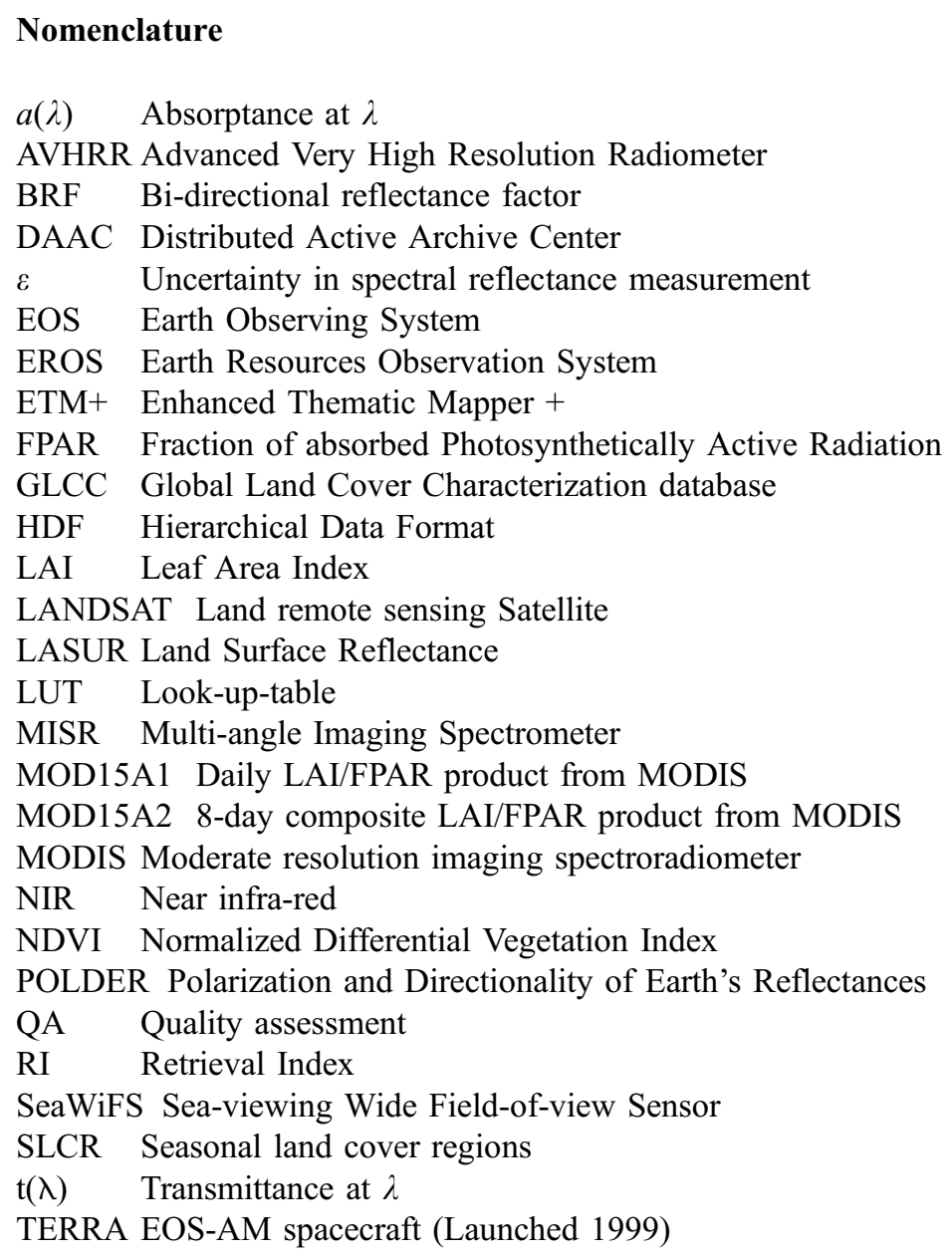

with the flexibility of using the same algorithm in MODISonly and MISR-only modes as well (Knyazikhin, Martonchik, Diner, et al., 1998; Knyazikhin, Martonchik, Myneni, et al., 1998).

In this paper, we provide an overview of the MODIS LAI/FPAR research. This includes a description of the salient features of the algorithm, evaluation of its performance, details of the product from year one of MODIS data and initial results of validation with field data. The MODIS LAI/FPAR product is currently being produced operationally and is available to the user community free of charge.

\section{The MODIS LAI/FPAR algorithm}

The operational MODIS algorithm ingests up to seven atmosphere-corrected surface spectral bi-directional reflectance factors (BRFs) and their uncertainties and outputs the most probable values for pixel LAI, FPAR and their respective dispersions. The theoretical basis of the algorithm is given in Knyazikhin, Martonchik, Myneni, et al. (1998) and the implementation aspects are discussed in
Knyazikhin et al. (1999). A look-up-table (LUT) method is used to achieve inversion of the three-dimensional radiative transfer problem. When this method fails to localize a solution, a back-up method based on relations between the normalized difference vegetation index (NDVI) and LAI/FPAR (Knyazikhin, Martonchik, Myneni, et al., 1998; Myneni, Hall, Sellers, \& Marshak, 1995) are utilized together with a biome classification map. The principal features of the LUT-based method are summarized below.

\subsection{Global biome map}

Global vegetation is stratified into six canopy architectural types, or biomes, in our approach to LAI/FPAR retrieval. The six biomes are grasses and cereal crops, shrubs, broadleaf crops, savannas, broadleaf forests and needle leaf forests. These biomes span structural variations along the horizontal (homogeneous vs. heterogeneous) and vertical (single- vs. multi-story) dimensions, canopy height, leaf type, soil brightness and climate (precipitation and temperature) space of herbaceous and woody vegetation globally. 
The biome map reduces the number of unknowns of the inverse problem through the use of simplifying assumptions (e.g., model leaf normal orientation distributions) and standard constants (e.g., leaf, wood, litter and soil optical properties) that are assumed to vary with biome and soil types only. This approach is similar to that adopted in many global models which assume certain key parameters to vary only by vegetation type and utilize a land cover classification to achieve spatialization. The assumption that vegetation within each $1 \mathrm{~km}$ MODIS pixel belongs to one of the six biomes impacts performance of the algorithm.

The translation of land cover classes into six biomes is ambiguous with respect to several classes. The only global map source with the requisite details is the Global Land Cover Characterization Data Base (GLCC) available from Earth Resources Observation System (EROS) Data Center (Loveland et al., 2000). Seasonal land cover regions (SLCR) provide a framework for aggregation into broader classes, e.g., the six biomes. To generate a six biome map, the Hansen, DeFries, Townshend, and Sohlberg (2000) classification map is used together with the SLCR map (Lotsch, Tian, Friedl, \& Myneni, in press). Specifically, for those classes in the Hansen et al. scheme that can be directly translated into one of the biomes, a direct class assignment is performed. For classes that do not allow a direct translation, the respective SLCR label is retrieved and a biome is assigned using an SLCR-biome look-up table. This is performed on a per-pixel basis. The SLCR labels are particularly useful for disaggregating the cropland class into broadleaf crops and cereal crops. The biome map thus obtained is shown in Fig. 1 and is used by the at-launch algorithm. The map will be updated by the MODIS biome map currently under development.

\subsection{Input uncertainties and solution distributions}

The LAI/FPAR algorithm compares MODIS directional spectral reflectances to comparable values evaluated from model-based entries stored in a look-up-table (LUT) and derives the distribution of all possible solutions, i.e., LAI and FPAR distribution functions. Mean and variance of the distribution functions are archived (Knyazikhin, Martonchik, Diner, et al., 1998). This is illustrated in Fig. 2, where the algorithm inputs are shown in the red and near-infrared space (panel a) and the outputs as solution distributions (panel b). A one-to-one match between the inputs and outputs is realized only in the case of error-free inputs, a perfect algorithm and sufficient information required to uniquely localize a solution (Zhang et al., 2000). For our problem, this is not the case.

First, two different locations in the input space can correspond to the same value of the output but different biome types, for example. The algorithm should account for differences in structure and optics of these biomes in a way that the same value of LAI is retrieved in both cases. Second, a point in the input space may correspond to multiple LAI values, because, for example, different combinations of LAI and soil types can result in the same value of canopy spectral reflectances. It means that the inputs do not contain sufficient information to localize a unique solution. Third, in the case of a dense canopy, its reflectance in one or several directions can be insensitive to various parameter values (e.g., LAI) characterizing the canopy because, for example, the reflectance of solar radiation from the underlying soil surface or lower leafstories is completely obscured by the upper leaves (Carlson and Ripley, 1997; Jasinski, 1996; Liu and Huete, 1995; Price, 1993). When this happens, the canopy reflectance is
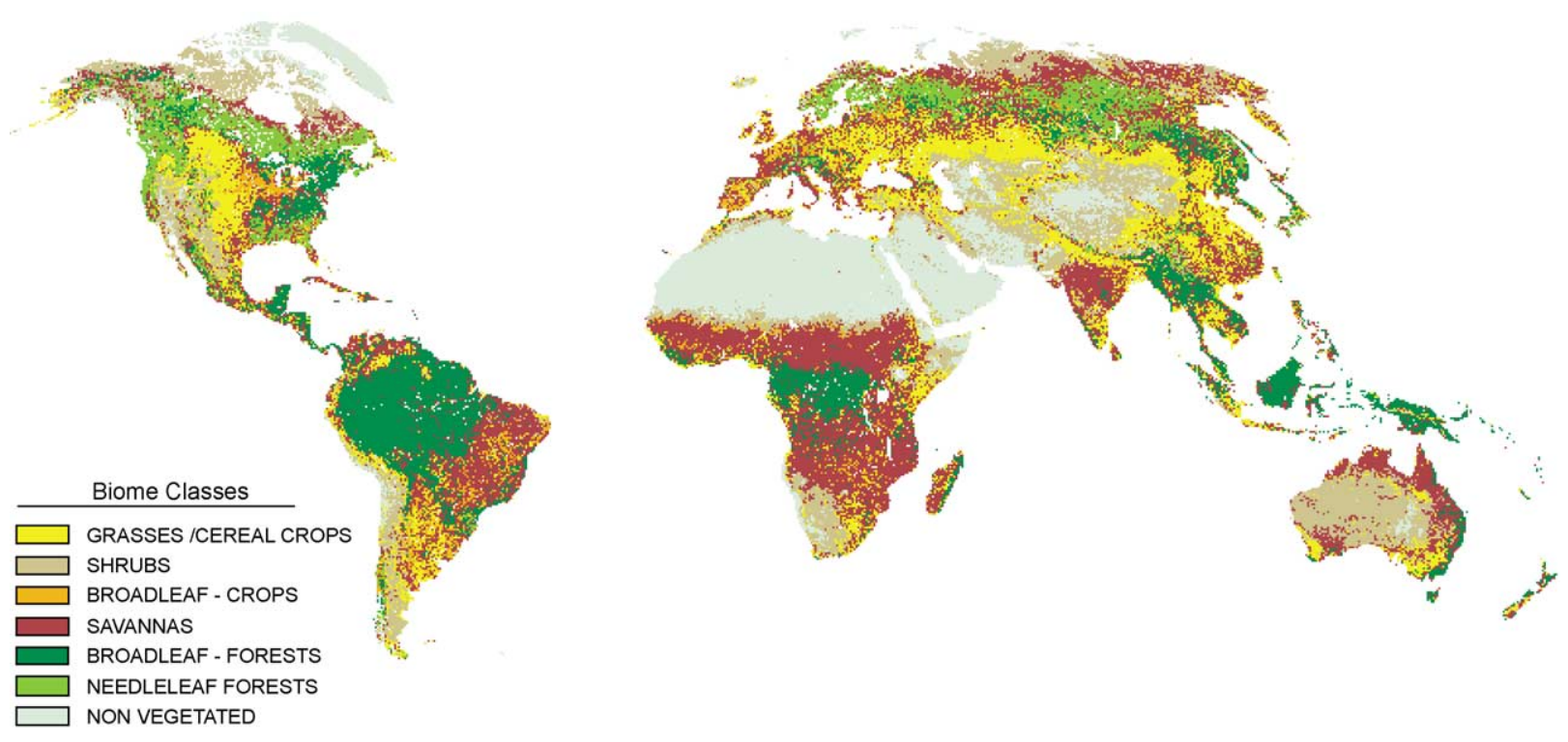

Fig. 1. Global $1 \mathrm{~km}$ six-biome map used by the MODIS LAI/FPAR algorithm. 
(a)

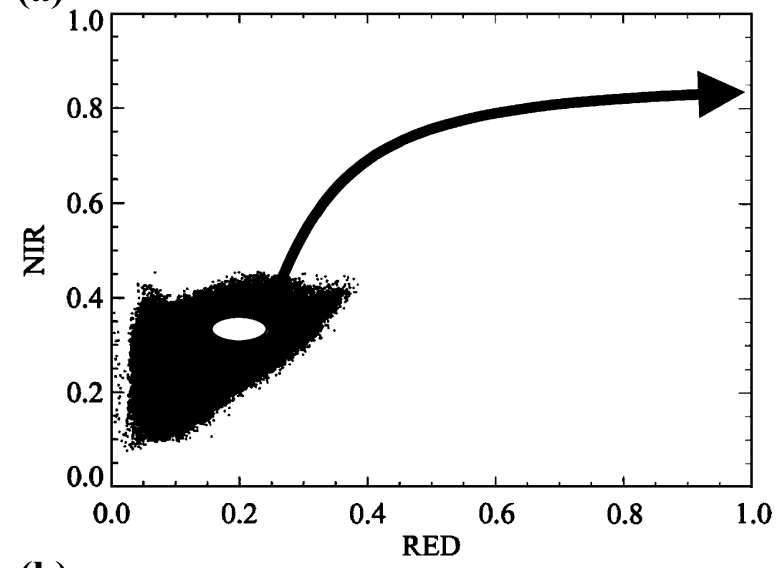

(b)

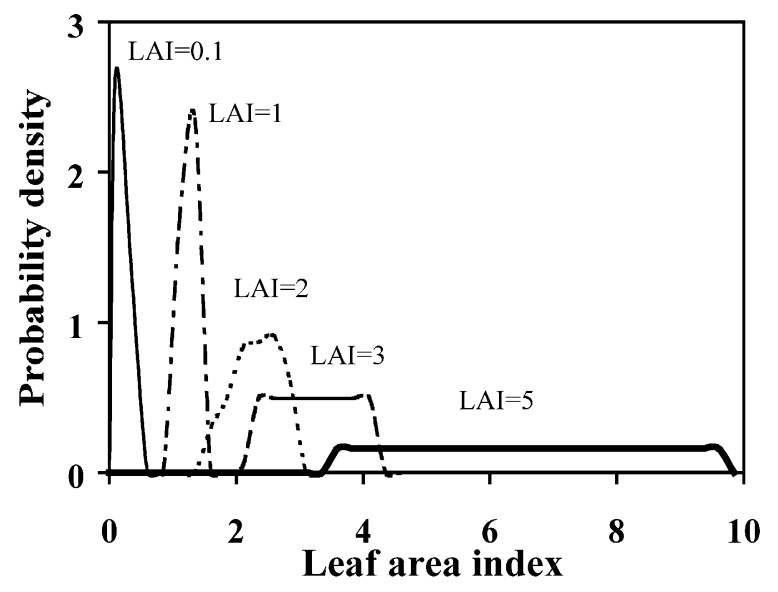

Fig. 2. (a) Distribution of vegetated pixels with respect to their reflectances at red and near infrared spectral bands derived from SeaWiFS data (September 22, 1997). A point on the red-NIR (near infrared) plane and an area about it (white ellipses defined by a $\chi^{2}$ distribution, Wang et al., 2001) can be treated as the measured BRF and uncertainty. Each canopy/soil pattern for which modeled reflectances belong to the ellipse shown is an acceptable solution. For each set of observed spectral reflectances and their uncertainties, one defines a cumulative solution distribution function $F(l)$ as the portion of LAI values which are less than $l$. (b) The solution density distribution function $\mathrm{d} F(l) / \mathrm{d}(l)$ for five different pixels. The mean LAI over this distribution and its dispersion are taken as the LAI retrieval and its uncertainty, respectively. The labels: $\mathrm{LAI}=0.1, \mathrm{LAI}=1, \mathrm{LAI}=2, \mathrm{LAI}=3$ and $\mathrm{LAI}=5$ indicate $\mathrm{LAI}$ values of the selected pixels.

said to belong to the saturation domain (Knyazikhin, Martonchik, Diner, et al., 1998). The distribution of LAI values will appear flat over the range of LAI, illustrating that the solutions all have equal probability of occurrence (case 5 Fig. 2b). Therefore, all LAI values greater than an input-dependent LAI value are valid solutions. More information must be provided to the algorithm in such cases to localize the solution (Zhang et al., 2000). Fourth, a unique solution cannot be expected in the general case of input uncertainties and algorithm imperfections. Thus, one can at best derive a distribution of possible solutions and characterize this distribution by its mean and variance. This is illustrated in Fig. 2 where the input plus its uncertainty are shown as an ellipse (panel a). Every point in this ellipse is a valid input. The algorithm evaluates all corresponding solutions, that is, the solution distribution function (panel $b$ ). The dispersion of this distribution is an index of retrieval quality, and is in general larger than input uncertainties.

\subsection{Energy conservation as a constraint}

The number of valid solutions may be unacceptably large in view of simplifying assumptions in the algorithm and errors in input data. Therefore, the constraint provided by the law of energy conservation on the inverse problem is valuable in obtaining meaningfully localized solutions (Knyazikhin, Martonchik, Diner, et al., 1998). This principle is utilized in the MODIS LAI/FPAR algorithm as follows. The model-based LUT entries are BRFs parameterized in terms of basic components of the energy conservation law, namely, canopy transmittance and absorptance whose spectral variation can be explicitly expressed via the leaf spectrum and two canopy structure specific wavelength-independent variables. This facilitates comparison of spectral values of BRFs with spectral properties of individual leaves, which is a rather stable characteristic of a green leaf. It allows the algorithm to admit only those LAI values for which the modeled BRFs agree with the energy conservation law at any wavelength of solar spectrum, thus allowing a significant reduction in the number of retrieved solutions. Extensive prototyping of the algorithm with data from different sensors (AVHRR, LANDSAT, SeaWiFS) indicates that this constraint significantly enhances the accuracy of LAI/FPAR retrievals (Tian et al., 2000; Wang et al., 2001).

\subsection{Spectral invariance}

The extinction coefficient in vegetation canopies was treated by Ross (1981) as wavelength-independent considering the size of the scattering elements (leaves, branches, twigs, etc.) relative to the wavelength of solar radiation. This spectral invariance results in a relation between canopy transmittance, $t\left(\lambda_{0}\right)$, and absorptance $a\left(\lambda_{0}\right)$ at a reference wavelength $\lambda_{0}$ to transmittances $t(\lambda)$ and absorptances $a(\lambda)$ at all other wavelengths $\lambda$ in the solar spectrum (Knyazikhin, Martonchik, Myneni, et al., 1998),

$$
\begin{aligned}
t(\lambda) & =\frac{1-\omega\left(\lambda_{0}\right) p_{t}}{1-\omega(\lambda) p_{t}} t\left(\lambda_{0}\right) \\
a(\lambda) & =\frac{1-\omega\left(\lambda_{0}\right) p_{a}}{1-\omega(\lambda) p_{a}} \frac{1-\omega(\lambda)}{1-\omega\left(\lambda_{0}\right)} a\left(\lambda_{0}\right)
\end{aligned}
$$

where $\omega$ is the sum of leaf hemispherical reflectance and transmittance (leaf albedo); $p_{t}$ and $p_{a}$ are canopy structuredependent variables (therefore wavelength-independent but spatial resolution-dependent). The importance of these 


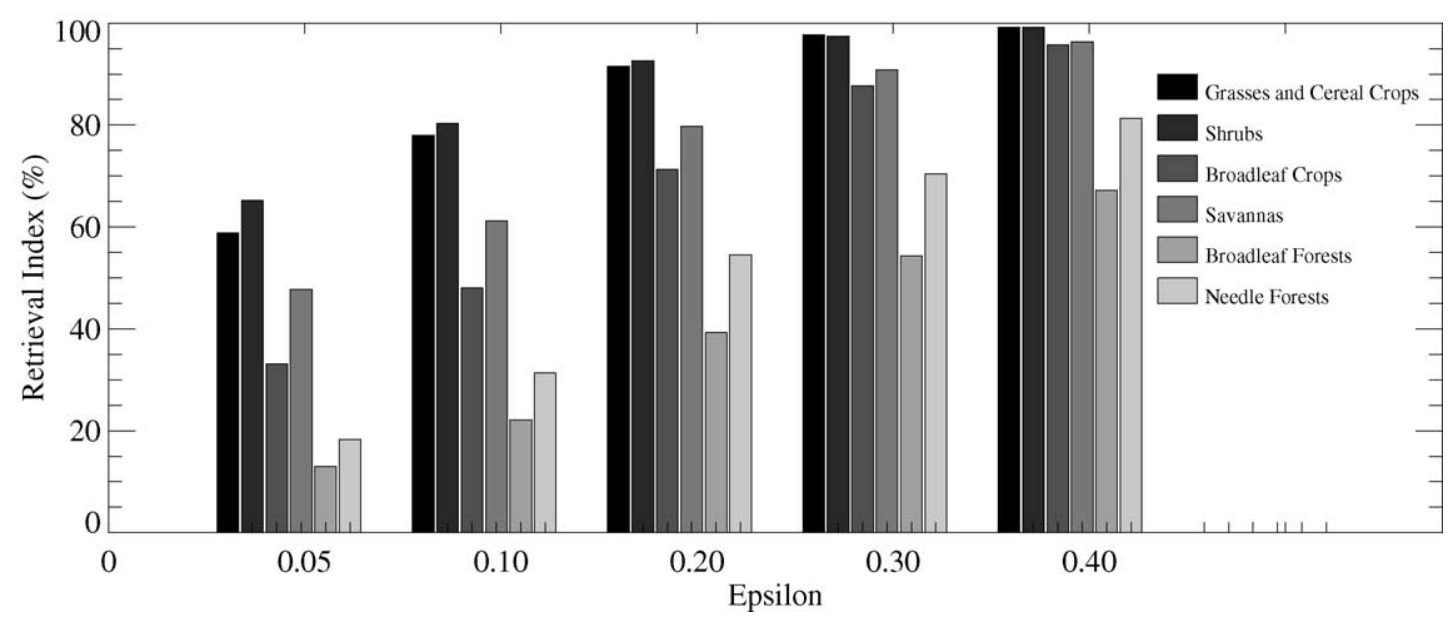

Fig. 3. The dependence of the Retrieval Index (RI) on relative uncertainties $(\varepsilon)$ in measurements and model simulations. The red and near-infrared reflectances input to the algorithm were from July 1989 LASUR data set (Berthelot et al., 1997).

relations is two-fold. The size of the LUT is independent of the number of spectrally dependent inputs ingested by the algorithm since wavelength dependencies can be resolved from reference wavelength entries and knowledge of $p_{t}$ and $p_{a}$. Second, the scale dependence of the LUT, because of $p_{t}$ and $p_{a}$, facilitates validation of coarse scale retrievals with fine scale field measurements, as discussed later.

\section{Performance of the MODIS LAI/FPAR algorithm}

In this section, we present results that illustrate the performance of the algorithm with respect to input and model uncertainties, multi-band retrievals, dependence on spatial resolution, impact of biome misclassifications, reflectance saturation, etc.

\subsection{Input and model uncertainties}

The uncertainties in input surface reflectances and models used to generate the LUT set a limit on the quality of retrievals. Their specification is critical to production of LAI and FPAR fields of maximum possible quality (Wang et al., 2001). The in-orbit radiances measured by space-borne sensors require corrections for calibration and atmospheric effects and this introduces uncertainty in the surface reflectance products.

Model uncertainty characterizes the ability of models to approximate natural variability, which in general can be quite high. These uncertainties depend on the temporal and spatial resolution of the data as well. Ignoring model uncertainties in a retrieval algorithm leads to destabilization of the convergence process because an increase in input

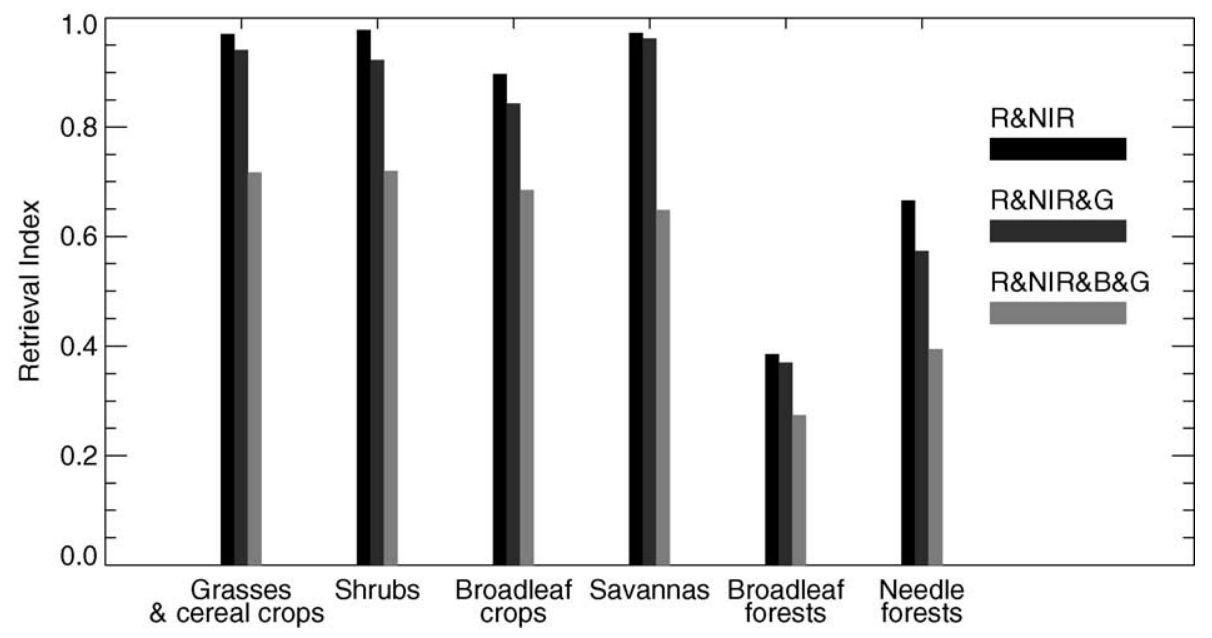

Fig. 4. Retrieval indices of two-, three- and four-band retrievals for various biomes with SeaWiFS data. The abbreviations R, NIR, G and B refer to red, nearinfrared, green and blue bands, respectively. The relative uncertainties were assumed to be 0.2 in all bands. 


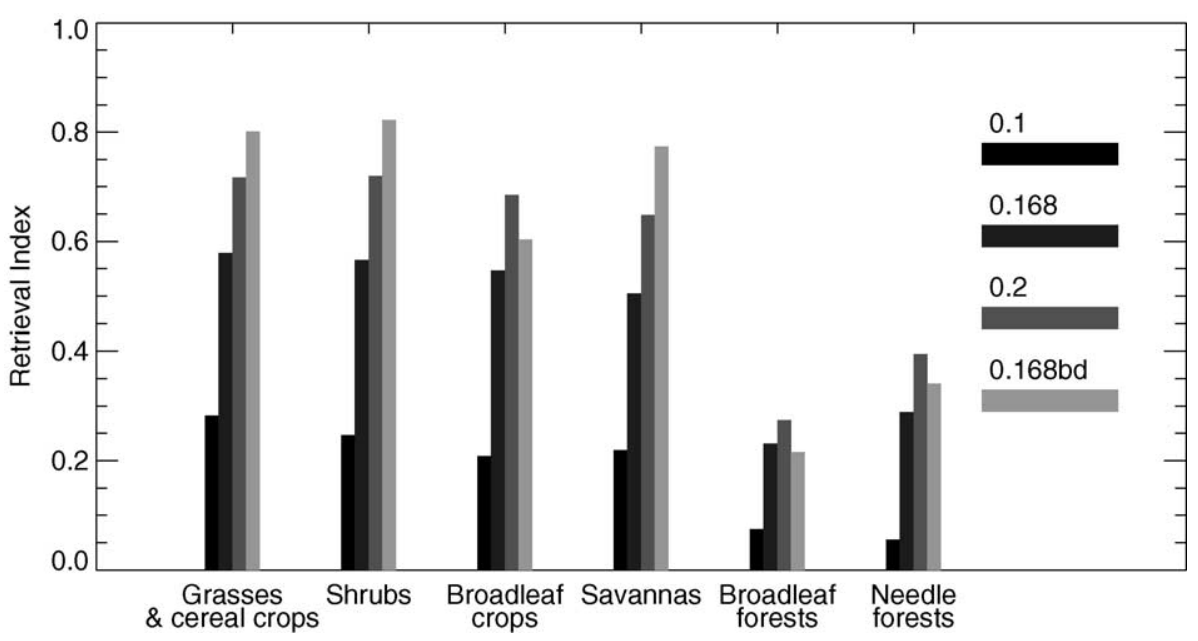

Fig. 5. Four-band retrieval indices for different values of relative uncertainties derived from SeaWiFS surface reflectances at red, near-infrared, green and blue spectral bands. The labels $0.1,0.168$ and 0.2 correspond to the cases when relative uncertainties in spectral reflectances were wavelength independent. The label 0.168 bd identifies retrieval indices obtained using band-specific uncertainties (values given in the text).

accuracy does not lead to better localization of the solutions (Wang et al., 2001).

The convergence property of an algorithm guarantees increasingly accurate retrievals with increasingly accurate inputs. To assure convergence, both input and model uncer-
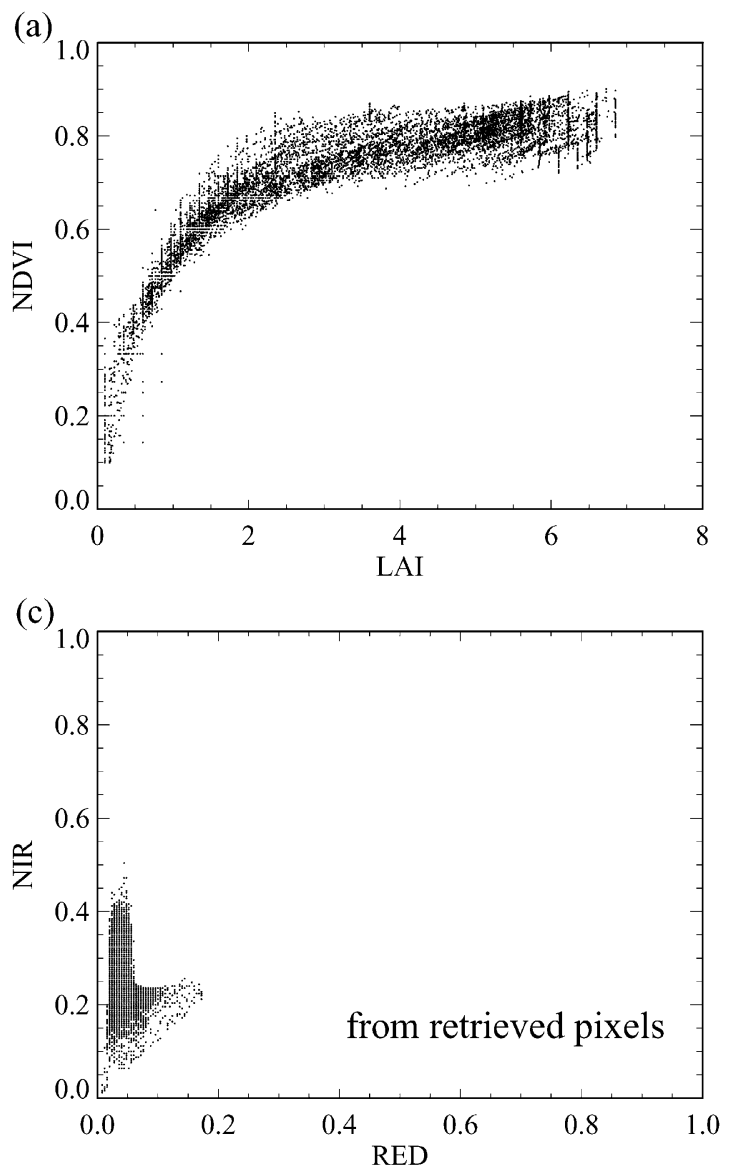

tainties should be known. In general, this is not the case, especially with respect to model uncertainties. Convergence can be assured by introducing a stabilization parameter, as described in Wang et al. (2001), which allows a correct specification of the overall uncertainty in the inverse prob-

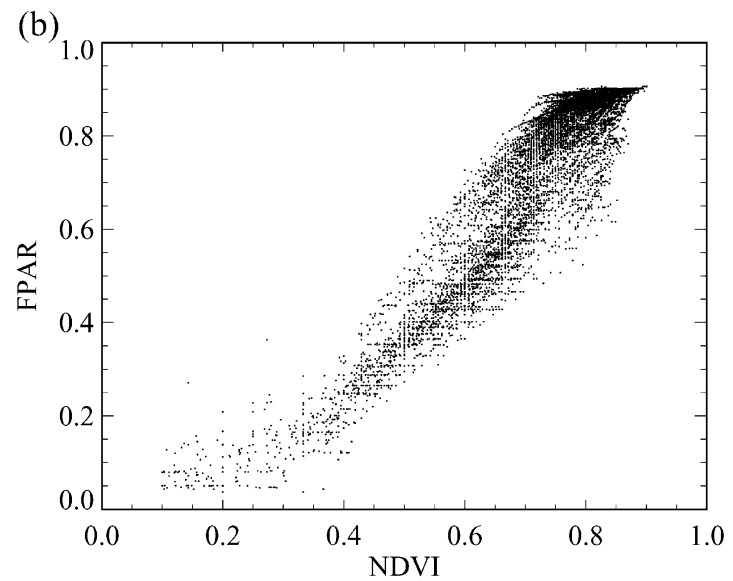

(d)

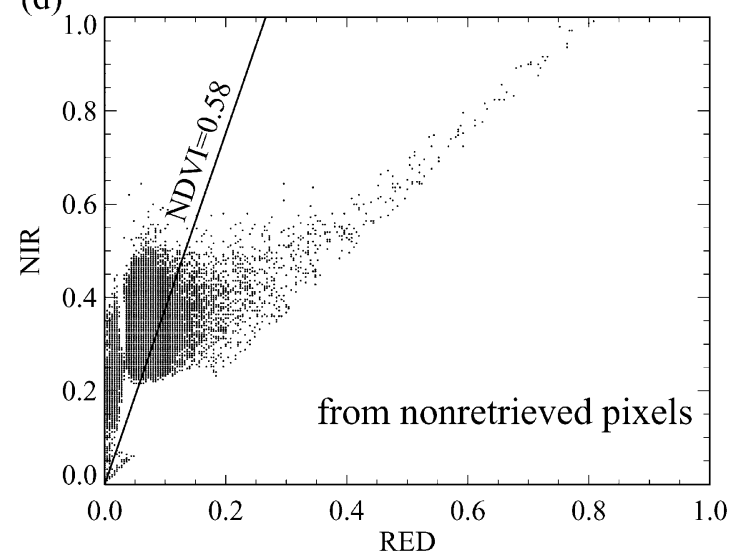

Fig. 6. For broadleaf forests, the scatter plot shows (a) the LAI-NDVI relationship, (b) NDVI-FPAR relationship, (c) retrieved and (d) non-retrieved pixels in RED-NIR space. The input reflectance data are July 1989 LASUR data set (Berthelot et al., 1997). 
Table 1

Effect of biome misclassification on LAI retrievals with data from the July 1989 LASUR data set (Berthelot et al., 1997)

\begin{tabular}{|c|c|c|c|c|c|c|}
\hline \multirow[t]{2}{*}{ Biome type } & \multicolumn{6}{|c|}{ Misclassified biome type } \\
\hline & $\begin{array}{l}\text { Grasses and } \\
\text { cereal crops }\end{array}$ & Shrubs & $\begin{array}{l}\text { Broadleaf } \\
\text { crops }\end{array}$ & Savannas & $\begin{array}{l}\text { Broadleaf } \\
\text { forests }\end{array}$ & $\begin{array}{l}\text { Needle } \\
\text { forests }\end{array}$ \\
\hline \multirow[t]{2}{*}{ Grasses and cereal crops } & 91.53 & 88.54 & 89.60 & 88.68 & 27.63 & 29.00 \\
\hline & 1.20 & 1.25 & 1.40 & 1.36 & 1.29 & 2.01 \\
\hline \multirow[t]{2}{*}{ Shrubs } & 87.67 & 92.66 & 91.53 & 91.73 & 47.34 & 46.37 \\
\hline & 1.03 & 1.41 & 1.54 & 1.51 & 1.51 & 1.99 \\
\hline \multirow[t]{2}{*}{ Broadleaf crops } & 87.93 & 70.33 & 74.03 & 71.29 & 14.80 & 19.52 \\
\hline & 1.85 & 1.83 & 2.10 & 2.04 & 2.42 & 3.71 \\
\hline \multirow[t]{2}{*}{ Savannas } & 78.02 & 79.91 & 80.25 & 79.65 & 41.31 & 44.33 \\
\hline & 1.51 & 2.08 & 2.29 & 2.25 & 2.22 & 2.95 \\
\hline \multirow[t]{2}{*}{ Broadleaf forests } & 55.02 & 63.23 & 61.40 & 61.32 & 39.30 & 33.59 \\
\hline & 1.92 & 3.30 & 3.44 & 3.45 & 4.01 & 4.65 \\
\hline \multirow[t]{2}{*}{ Needle forests } & 76.75 & 85.74 & 84.92 & 84.78 & 46.38 & 54.54 \\
\hline & 1.64 & 2.92 & 3.21 & 3.18 & 2.98 & 4.00 \\
\hline
\end{tabular}

The two entries in each box are the Retrieval Index and the mean LAI values, respectively.

lem. The quality of retrieval is a function of the overall uncertainty, denoted here as $\varepsilon$.

We define a measure, termed the Retrieval Index (RI), as the number of pixels for which the algorithm reports a solution relative to the total number of attempted pixels. This variable does not characterize the quality of LAI and FPAR fields, but shows the global coverage of the retrieved LAI and FPAR fields. The RI increases with an increase in $\varepsilon$, but the reliability of retrievals decreases (Fig. 3). If $\varepsilon$ underestimates the true overall uncertainty, the algorithm fails to localize a solution, thus resulting in low values of RI. On the other hand, if $\varepsilon$ is an overestimate the algorithm admits a large number of solutions, including non-physical solutions, thus resulting in high values of RI. A critical value of $\varepsilon$ is one that optimally approximates the unknown true overall uncertainty. This is estimated as the value of $\varepsilon$ for which $95 \%$ of all land pixels for which the algorithm fails were non-vegetated areas or regions where the data were corrupted due clouds or atmospheric effect (Tian et al., 2000; Wang et al., 2001).

\subsection{Multi-band retrievals}

We further illustrate the importance of characterizing uncertainties in input spectral reflectances through multiband algorithm retrievals with SeaWiFS data (Wang et al., 2001). Let us assume an overall relative uncertainty of $20 \%$ in red, near-infrared, green and blue bands $(\varepsilon=0.2)$. The RI values for two-, three- and four-band retrievals are shown in Fig. 4. The RI decreases dramatically when the blue band is included because of the strong atmospheric effect which increases the uncertainty. Since this was assumed to be 0.2 , the overall uncertainty was substantially underestimated, resulting in a decrease of RI.

Uncertainties in the surface reflectance product can be estimated from the atmospheric correction algorithm (Vermote et al., 1997). Typical values of uncertainties in surface reflectance are $10-33 \%$ at red, 3-6\% at near-infrared, 5$12 \%$ at green and $50-80 \%$ at blue. The overall relative uncertainty is $16.8 \%$. Fig. 5 demonstrates the four-band Retrieval Index as a function of biome type and uncertain-

Table 2

Retrieval indices and mean LAI values from algorithm runs on LANDSAT and LASUR data with LANDSAT and LASUR LUTs

\begin{tabular}{|c|c|c|c|c|}
\hline \multicolumn{5}{|l|}{ LASUR data } \\
\hline \multirow[t]{2}{*}{ Biome type } & \multicolumn{2}{|l|}{ LASUR LUT } & \multicolumn{2}{|l|}{ LANDSAT LUT } \\
\hline & Retrieval index & Mean LAI & Retrieval index & Mean LAI \\
\hline Grasses and cereal crops & 91.53 & 1.20 & 91.6 & 1.07 \\
\hline Shrubs & 92.66 & 1.41 & 96.4 & 0.92 \\
\hline Broadleaf crops & 74.03 & 2.09 & 80.1 & 1.17 \\
\hline Savannas & 79.65 & 2.25 & 85.4 & 1.61 \\
\hline Broadleaf forests & 39.30 & 4.01 & 41.8 & 2.62 \\
\hline Needle forests & 54.54 & 3.99 & 41.8 & 1.66 \\
\hline \multicolumn{5}{|l|}{ LANDSAT data } \\
\hline \multirow[t]{2}{*}{ Biome type } & \multicolumn{2}{|l|}{ LANDSAT LUT } & \multicolumn{2}{|l|}{ LASUR LUT } \\
\hline & Retrieval index & Mean LAI & Retrieval index & Mean LAI \\
\hline Grasses and cereal crops & 90.7 & 1.87 & 87.5 & 3.62 \\
\hline Broadleaf forests & 53.9 & 5.79 & 39.2 & 6.21 \\
\hline Needle forests & 57.9 & 4.11 & 4.7 & 3.39 \\
\hline
\end{tabular}


Table 3

Retrieval Index and frequency of LAI under saturation for POLDER data (1-16 November, 1996) over Africa with mean overall uncertainty of 0.2

\begin{tabular}{|c|c|c|c|c|c|c|}
\hline & \multirow[t]{2}{*}{ No. of view angles } & \multicolumn{5}{|c|}{ BCM biome type } \\
\hline & & $\begin{array}{l}\text { Grasses and } \\
\text { cereal crops }\end{array}$ & Shrubs & $\begin{array}{l}\text { Broadleaf } \\
\text { crops }\end{array}$ & Savannas & $\begin{array}{l}\text { Broadleaf } \\
\text { forests }\end{array}$ \\
\hline \multirow[t]{2}{*}{ Retrieval Index } & 1 & 99.5 & 99.90 & 99.2 & 98.1 & 40.6 \\
\hline & 6 & 84.0 & 80.8 & 73.4 & 74.9 & 18.9 \\
\hline \multirow[t]{2}{*}{ LAI saturation frequency } & 1 & 0.01 & 0.02 & 6.26 & 9.76 & 30.1 \\
\hline & 6 & 0.0 & 0.01 & 2.52 & 6.18 & 17.4 \\
\hline
\end{tabular}

ties. The retrieval labeled $0.168 \mathrm{bd}$ denotes that information on band specific uncertainties was used by the retrieval technique, unlike other retrievals in this figure where these were equal in all four bands. The RI values increase with increase in overall uncertainty, as noted previously (cf. Fig. 3). Importantly, the case with band-specific uncertainties has a higher RI value compared to retrievals with band-independent uncertainties. This highlights the importance of characterizing band uncertainties in order to improve quality of LAI and FPAR maps.

\subsection{NDVI and LAI/FPAR relations}

The non-linear relation between NDVI and LAI and the near-linear relation between NDVI and FPAR reported in several studies has a physical basis as described in Myneni et al. (1995) and Knyazikhin, Martonchik, Myneni, et al. (1998). Therefore, we examine the relation between NDVI evaluated with red and near-infrared reflectances input to the algorithm and the retrieved LAI/FPAR values to test the physics of the algorithm.

Fig. 6 shows the distributions of the retrieved LAI and FPAR values with respect to the NDVI in the case of broadleaf forests. Indeed, the relations between retrieved LAI/FPAR and measured NDVI conform to both theoretical and empirical expectations. The scatter in the relations highlights the merit of the algorithm vs. a direct estimation from NDVI. Panels c and d of Fig. 6 show scatter plots of input reflectance data from successful and unsuccessful retrievals in the red and near-infrared space. This distribution provides insight on where and why the algorithm failed.

For successful retrievals, the surface reflectances range from about $0.02-0.16$ in the red band and $0.10-0.42$ in the near-infrared band. The algorithm tends to fail when (a) the red reflectance is less than 0.03 , i.e., the NDVI is very large, (b) red and near-infrared reflectances both large, i.e., pixels are near the soil line and the NDVI is small, and (c) intermediate cases. If the red reflectance is too small, the uncertainty is large and the probability of a retrieval decreases. When a pixel is near the soil line, it is probably either a non-vegetated pixel or the data is corrupted by clouds, and the algorithm correctly identifies such cases. To understand the behavior of the algorithm for intermediate values of reflectances, consider the NDVI contour as shown in panel d. For the same value of NDVI, some pixels result in a retrieval while the others not. That is, the algorithm utilizes information on canopy spectral and structural properties, instead of NDVI, especially when it ingests three, four or even seven spectral bands and multi-angle data. Only when a pixel falls within the spectral and angular space specified in the LUT, a value for LAI is retrieved. Else, the algorithm returns a failure, even if the NDVI is reasonable. It is likely that the non-retrievals correspond to biome mixtures, whose probability is larger at coarse resolutions.

\subsection{Impact of biome misclassification}

The assumption that vegetation within each pixel belongs to one of the six biomes impacts the LAI/FPAR retrievals. Results shown in Table 1 were obtained by running the algorithm six times per pixel, each time with a different biome's LUT. This simulates the effects of biome misclassification on the retrievals. With misclassification, either the RI is low and/or the retrieved LAI values are incorrect. In case of misclassification between distinct biomes, the results are predictable. Consider grasses and cereal crops (biome 1) and broadleaf forests (biome 5), which are distinct in their architecture and foliage optics. When biome 1 is misclassified as biome 5 , the RI is only $27 \%$ compared to $91 \%$ without misclassification. When biome 5 is misclassified to biome 1 , the retrieved LAI value decreases from 4 or 5 to 2 . Thus, misclassification can be detected by RI, mean LAI and the histogram of the retrieved LAI distribution. On the other hand, when misclassification happens between spectrally and structurally similar biomes, perhaps because of coarse spatial resolution, the impact on LAI/FPAR retrievals is difficult to assess. For example, consider shrubs (biome 2) and savannas (biome 4). The RI does not change much and the mean LAI is also similar. Thus, the retrieved LAI/FPAR values are accept-

Table 4

Summary of the MODIS LAI/FPAR Scientific Data Sets (SDS)

\begin{tabular}{llllll}
\hline SDS variable & Data type & Fill value & Gain & Offset & Valid range \\
\hline Fpar_1 km & Uint8 & 255 & 0.01 & 0.0 & $0-100$ \\
Lai_1 km & Uint8 & 255 & 0.10 & 0.0 & $0-100$ \\
FparLai_QC & Uint8 & 255 & N/A & 0.0. & $0-254$ \\
FparExtra_QC & Uint8 & 255 & N/A & 0.0 & $0-254$ \\
\hline
\end{tabular}

The expression used to decode the Digital Numbers to the corresponding analytical value is: analytical $l_{\text {value }}=\operatorname{scale}_{\text {factor }} \times\left(\right.$ digital $_{\text {number }}-$ offset $)$. 
able, although the pixels have been misclassified. Such a case also indicates that the biome LUTs share similar entries for certain combinations of spectral reflectances. This may be an indication of the limitations of the model used to build the LUT. Another limitation may be characterizing global vegetation as six architectural biome types, and not allowing for mixtures, which is especially an acute problem with coarse resolution retrievals.

\subsection{Scale dependence of the algorithm}

Reflectance of the vegetation canopy is scale-dependent. With a decrease in spatial resolution of satellite data, the pixels are likely to contain an increasing amount of radiative contribution from the background (Tian et al., 2000). This manifests as changes in the location of reflectance data in the spectral space with changing spatial resolution. Understanding the relation between such changes and LAI/FPAR variations with resolution is key to accomplishing the scaling that is required in the validation of large area retrievals with point field measurements. The MODIS LAI/FPAR algorithm addresses this issue explicitly through structure-dependent parameters $p_{t}$ and $p_{a}$, introduced earlier, which imbue scale dependence to the algorithm via modifications to the LUTs (Tian et al., 2000).

The scale dependence of the algorithm is illustrated here with retrievals from algorithm runs on LANDSAT data with both LANDSAT $(30 \mathrm{~m})$ and LASUR (atmospherically corrected LAnd SUrface Reflectances in the red and nearinfrared channels of the Advanced Very High Resolution Radiometer (AVHRR) at global scale, $1 / 7^{\circ}$ resolution; 1 week temporal resolution for 1989) LUTs, and on LASUR data with LANDSAT and LASUR LUTs (Table 2). When Landsat data and LUT are used, the retrieved LAI values vary from 0 to 2.5 for grasses, $5-7$ for broadleaf forests and $1.5-6$ for needle forests. The same runs with LASUR LUT result in unrealistic retrievals-large LAI values and/or low retrieval indices because the location of fine resolution data even in low LAI canopies map to locations of coarse resolution reflectance data of dense canopies. Likewise, algorithm runs on LASUR data with LANDSAT LUT result in low values of LAI for all biomes.

The probability of spatially variable background in a coarse resolution cell is larger in comparison to fine resolution data. Coarse resolution reflectance data, therefore, have larger radiative contributions from the background. While the LAI of the imaged scenes may be identical, the location of reflectance data in the spectral space changes with resolution. In the design of the MODIS LAI/FPAR algorithm, the three-dimensional radiative transfer problem is split into two sub-problems. The first, the black-soil problem, describes a vegetation radiation regime for the case of a completely absorbing background beneath the canopy. The second, the S-problem, describes the radiation regime due to interactions between the underlying surface and the canopy that includes contributions from the background. At finer resolutions, the contribution of the S-problem is negligible, especially at high LAI values. For example, the retrieval indices from LANDSAT data and LUT runs can be as high as $51 \%$ (broadleaf forests) using just the black-soil

Table 5

Summary of MODIS LAI/FPAR quality control variables. The Dead Detector bit was added as of September 13, 2000

\begin{tabular}{|c|c|c|c|}
\hline Variable & Bitfield & $\begin{array}{l}\text { Binary, } \\
\text { decimal } \\
\text { values }\end{array}$ & $\begin{array}{l}\text { Description } \\
\text { of bitfield(s) }\end{array}$ \\
\hline \multirow[t]{16}{*}{ FparLai_QC } & \multirow[t]{4}{*}{ MODLAND 0,1 } & $00=0$ & $\begin{array}{l}\text { Highest } \\
\text { overall Quality }\end{array}$ \\
\hline & & $01=1$ & Saturation \\
\hline & & $10=2$ & $\begin{array}{l}\text { Not produced, } \\
\text { cloud }\end{array}$ \\
\hline & & $11=3$ & $\begin{array}{l}\text { Not able to } \\
\text { produce }\end{array}$ \\
\hline & \multirow[t]{2}{*}{ ALGOR_PATH } & $0=0$ & $\begin{array}{l}\text { Empirical method } \\
\text { used }\end{array}$ \\
\hline & & $1=1$ & $\begin{array}{l}\mathrm{R}-\mathrm{T} \text { Main method } \\
\text { used }\end{array}$ \\
\hline & * DEAD- & $0=0$ & No dead detectors \\
\hline & DETECTOR & $1=1$ & Dead detector \\
\hline & \multirow[t]{4}{*}{ CLOUDSTATE } & $00=0$ & Cloud few \\
\hline & & $01=1$ & $\begin{array}{l}\text { Cloud covered } \\
\text { pixel }\end{array}$ \\
\hline & & $10=2$ & $\begin{array}{l}\text { Mixed clouds } \\
\text { present }\end{array}$ \\
\hline & & $11=3$ & Not set, assume clear \\
\hline & \multirow[t]{4}{*}{ SCF_QC } & $00=0$ & Best model result \\
\hline & & $01=1$ & $\begin{array}{l}\text { Good quality, not the } \\
\text { best }\end{array}$ \\
\hline & & $10=2$ & $\begin{array}{l}\text { Use with caution, see } \\
\text { other QA }\end{array}$ \\
\hline & & $11=3$ & $\begin{array}{l}\text { Could not retrieve } \\
\text { with either method }\end{array}$ \\
\hline \multirow[t]{16}{*}{ FparExtra_QC } & \multirow[t]{4}{*}{ LANDMASK } & $00=0$ & Land (terrestrial class) \\
\hline & & $01=1$ & $\begin{array}{l}\text { Shoreline, shallow } \\
\text { water }\end{array}$ \\
\hline & & $10=2$ & $\begin{array}{l}\text { Freshwater, inland } \\
\text { lakes }\end{array}$ \\
\hline & & $11=3$ & Ocean \\
\hline & \multirow[t]{2}{*}{ SNOW_ICE } & $00=0$ & $\begin{array}{l}\text { Significant snow } \\
\text { detected }\end{array}$ \\
\hline & & $01=1$ & No snow on pixel \\
\hline & \multirow[t]{2}{*}{ AEROSOL } & $00=0$ & $\begin{array}{l}\text { Low or no aerosol } \\
\text { on pixel }\end{array}$ \\
\hline & & $01=1$ & $\begin{array}{l}\text { Medium or high } \\
\text { aerosol on pixel }\end{array}$ \\
\hline & \multirow[t]{2}{*}{ CIRRUS } & $00=0$ & $\begin{array}{l}\text { No cirrus cloud } \\
\text { detected }\end{array}$ \\
\hline & & $01=1$ & $\begin{array}{l}\text { Cirrus clouds } \\
\text { present }\end{array}$ \\
\hline & \multirow[t]{2}{*}{$\begin{array}{l}\text { ADJACENT- } \\
\text { CLOUD }\end{array}$} & $00=0$ & $\begin{array}{l}\text { No adjacent clouds } \\
\text { detected }\end{array}$ \\
\hline & & $01=1$ & $\begin{array}{l}\text { Adjacent clouds } \\
\text { detected }\end{array}$ \\
\hline & \multirow[t]{2}{*}{ CLOUDSHADOW } & $00=0$ & $\begin{array}{l}\text { No cloud shadow } \\
\text { detected }\end{array}$ \\
\hline & & $01=1$ & $\begin{array}{l}\text { Cloud shadow was } \\
\text { detected }\end{array}$ \\
\hline & \multirow[t]{2}{*}{ SCF_MASK } & $00=0$ & User mask bit un-set \\
\hline & & $01=1$ & User mask bit set \\
\hline
\end{tabular}


problem compared to $54 \%$ when the S-problem is included. With coarse resolution LASUR data, however, the RI values for just the black-soil problem are low (31\%), which highlights the importance of background contributions.

\subsection{Reflectance saturation}

In the case of dense canopies, the reflectances saturate, and are therefore insensitive to changes in LAI. The canopy reflectances are then said to belong to the saturation domain (Knyazikhin, Martonchik, Diner, et al., 1998). The reliability of parameters retrieved under conditions of saturation is low, that is, the dispersion of the solution distribution is large (Fig. 2, case 5). The frequency of LAI retrievals under saturation also increases with increasing uncertainties. The saturation domain can be avoided if more information can be provided to the algorithm in the form of multi-angle and multi-spectral data (Zhang et al., 2000). Below, we illustrate the saturation domain problem with multi-angle retrievals.

Example algorithm runs with multi-spectral, multi-angle data over Africa from the POLDER instrument (Leroy et al., 1997), assuming a mean overall uncertainty of $20 \%$, were performed. The LAI saturation frequency decreases with an increase in the number of view angles (Table 3). This is evidence of the enhanced information content of multi-angle data, as it helps localize a value of LAI. As expected, the saturation domain is rarely encountered in sparse biomes, such as grasses and shrubs.

Saturation domain retrievals are flagged in the quality assessment (QA) files accompanying the MODIS LAI/ FPAR product. For each such retrieval, the lower bound of the LAI domain can be evaluated (Knyazikhin, Martonchik, Diner, et al., 1998). This value is to be interpreted as follows: all values of LAI above this threshold, up to the
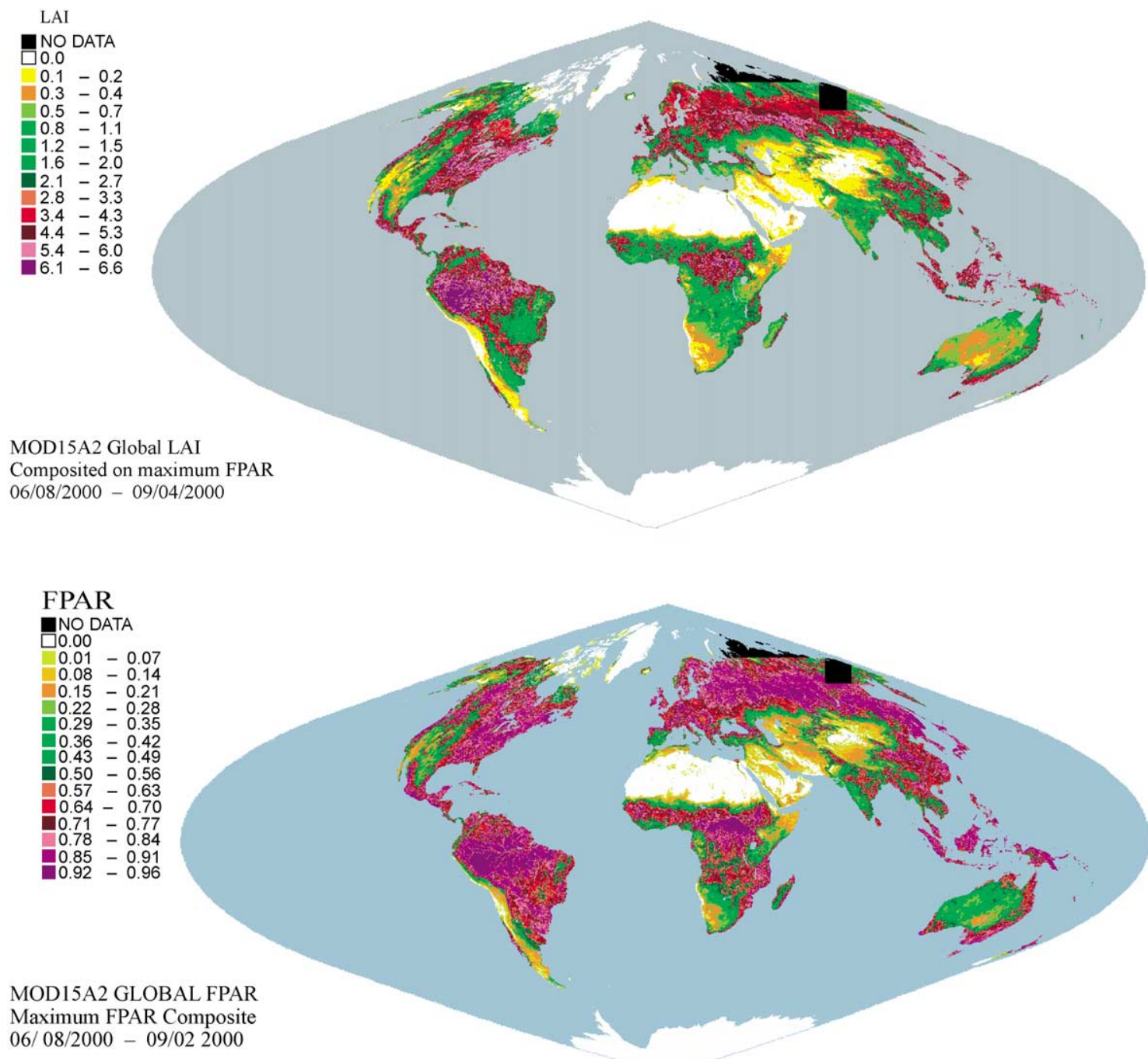

Fig. 7. Color-coded maps of MODIS LAI and FPAR fields for the boreal summer of year 2000 . Each pixel in the image is the average of $30 \times 30 \mathrm{MODIS}$ pixels (water pixels not included). The maximum FPAR value from the set of MOD15A2 data was chosen for each pixel for the FPAR image. The LAI value from the same date as the maximum FPAR value was chosen for the LAI image. 
maximum value of 7.0, are valid solutions (see case 5 in Fig. 2a). The algorithm reports a value equal to the arithmetic mean of these solutions.

\section{The MODIS LAI/FPAR product}

The MODIS LAI/FPAR product is produced at $1 \mathrm{~km}$ spatial resolution daily (MOD15A1) and composited over an 8-day period based on the maximum FPAR value. The 8day product (MOD15A2) is distributed to the public from the EROS Data Center Distributed Active Archive Center (EDC DAAC). The products are projected on the Integerized Sinusoidal (IS) $10^{\circ}$ grid, where the globe is tiled for production and distribution purposes into 36 tiles along the east-west axis, and 18 tiles along the north-south axis, each approximately $1200 \times 1200 \mathrm{~km}$.

The product files contain four scientific data sets, output as two-dimensional HDF EOS grid fields of 1200 lines by 1200 samples. All fields are produced using the HDF uint8 data type, which is an unsigned 8-bit integer variable whose values may range from 0 to 255 . The values are stored in

\section{LAI, TILE:H11V09}

DATE: July 3, 2000 - July 10, 2000

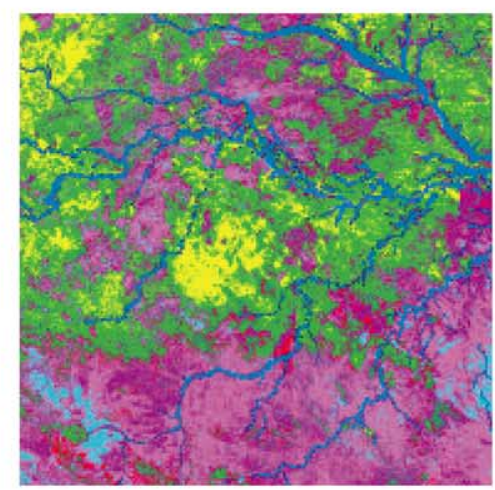

LAI, TILE:H11V09

DATE: July 19, 2000 - July 26, 2000

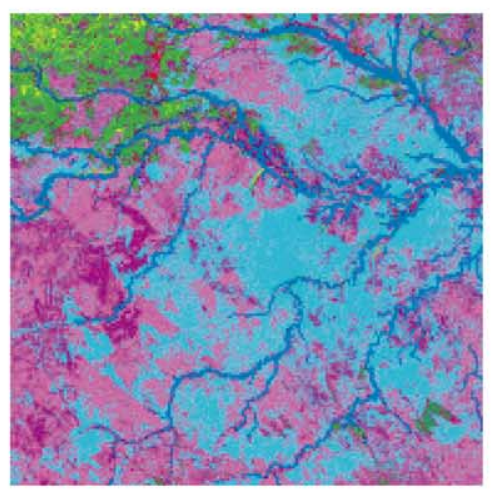

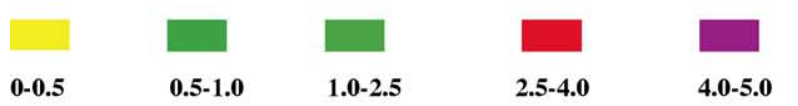

QA, TILE:H11V09

DATE: July 3, 2000 - July 10, 2000

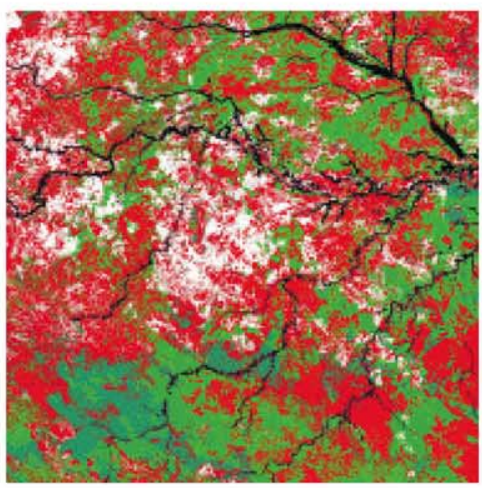

cloud

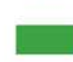

main algorithm (clear)

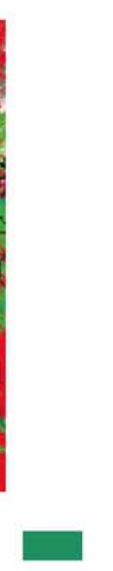

saturation (clear)

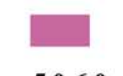

5.0-6.0
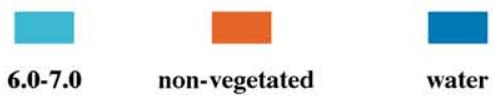

fill value

Fig. 8. The 8-day composite MODIS LAI product for a region in the Amazonia for two periods in July 2000. The corresponding quality assessment (QA) fields are shown in the two panels below. The main algorithm is the look-up-table (LUT)-based method and the backup algorithm is the NDVI-based method. The latter is used when the main algorithm fails. Note the low LAI values in the tile center during the early period due to clouds. 
their digital form with a scale-factor (gain) and offset, which is applied to transform the stored values to their biophysical counterparts for analysis. The quality control variables are integer measures without a gain or offset (Table 4). The product files also contain a considerable amount of extra information that describes various properties of the data. The majority of this information is classic metadata, describing the geolocation, quality, and source of the tile and pixel data.

Within the MODIS team, considerable attention has been paid to implement a set of quality control protocols that help users match data sets to their applications. Quality control measures are produced at both the file $\left(10^{\circ}\right.$ tile level $)$ and at the pixel level. At the tile level, these appear as a set of EOSDIS core system (ECS) metadata fields. At the pixel level, quality control information is represented by one or more separate data layers in the HDF EOS file whose pixel values correspond to specific quality scoring schemes that vary by product. The quality assessment (QA) organization users will find MOD15A2 files generated summarized in Table 5.

The LAI and FPAR products have been produced since MODIS started acquiring data in late February of 2000. The products have been released and are available free of charge to the users since early August 2000. Extensive documentation describing the availability and usage of the products can be found at the MODIS, EDC DAAC and MODIS LAND web sites (Justice et al., 2000). Global maps of MODIS LAI and FPAR for the boreal summer period are shown in Fig. 7.

The products from year one of MODIS operation should be used with caution in view of changes to calibration, geolocation, cloud screening, atmospheric correction and ongoing validation activities. In particular, the users are

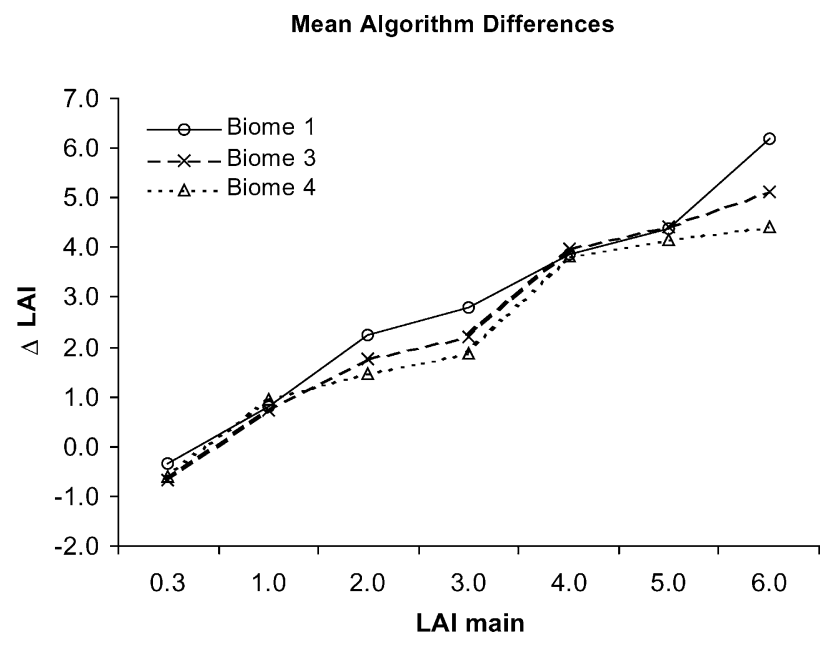

Fig. 9. Differences $\Delta \mathrm{LAI}=\mathrm{LAI}_{\text {main }}-\mathrm{LAI}_{\text {backup }}$ between values produced by the main $\left(\mathrm{LAI}_{\text {main }}\right)$ and by the backup ( $\mathrm{LAI}_{\text {backup }}$ ) algorithm as a function of values from the main algorithm for grasses and cereal crops (biome 1), broadleaf crops (biome 3), and savannas (biome 4). Data derived from MOD15A1 tiles for six pairs of days for two tiles from central Africa.

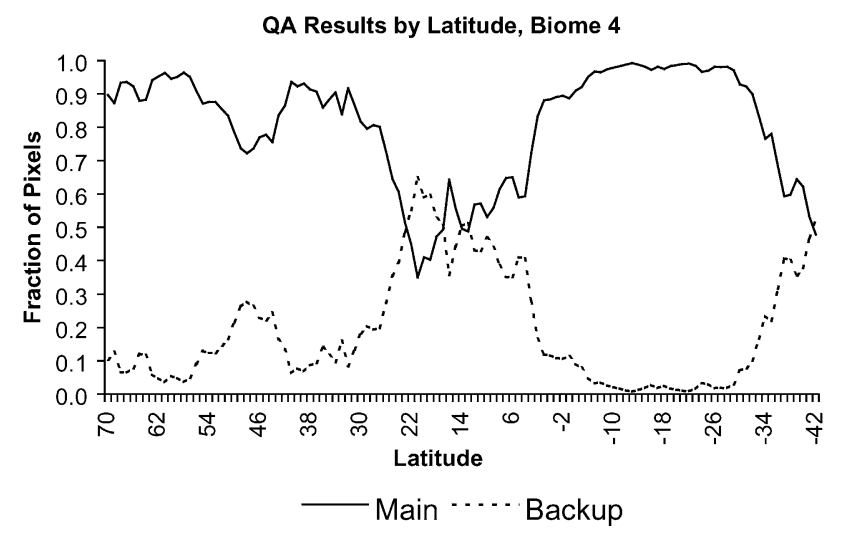

Fig. 10. Average QA value of pixels as a function of latitude. Chart is an average of the values from four A2 global coverage periods, whose initial dates are June 25, July 19, August 20 and August 28. For each degree of latitude, all pixels in each QA condition, that were marked as 'not cloudy,' are divided by the total number of non-cloudy pixels for that biome at that latitude. Saturation condition is not considered a separate condition here.

advised to pay attention to the QA files accompanying the products (see Table 5). For example, the MODIS LAI product for a region in the Amazonia is shown in Fig. 8 for two composite periods in July of 2000. Large variations in the LAI of tropical humid forests can be seen within the same month. The respective QA files, also shown in Fig. 8, indicate that the low LAI values correspond to retrievals under cloudy conditions.

Further evidence for the need to consult the QA files is shown with our analysis of the distribution of values produced by the backup relative to those produced by the main algorithm. Using two sets of consecutively dated MOD15A1 tiles, a difference $\Delta \mathrm{LAI}=\mathrm{LAI}_{\text {main }}-\mathrm{LAI}_{\text {backup }}$ was calculated for every pixel where the 2 days were marked cloud-free, 1 day was produced with the main LUT algorithm and the other produced through the backup NDVI-based algorithm. Plotting these differences against the value of the main algorithm shows that as they increase, the backup values increasingly lag behind (Fig. 9). For all these curves, $\Delta \mathrm{LAI} \approx \mathrm{LAI}_{\text {main }}$ (i.e., $\mathrm{LAI}_{\text {backup }} \approx 0$ ). Little variation in physical condition of land cover can be expected on a $1 \times 1 \mathrm{~km}$ scale over a $24-\mathrm{h}$ period. Therefore,

Table 6

Correlation between average (main-backup) differences and gradated values of LAI and FPAR produced by the main algorithm for each difference

\begin{tabular}{llcl}
\hline Biome type & $\begin{array}{l}\text { Retrieval } \\
\text { Index (\%) }\end{array}$ & $\begin{array}{l}\text { Saturation } \\
\text { Index (\%) }\end{array}$ & Mean LAI \\
\hline Grasses and cereal crops & 91.3 & 0.0 & 0.74 \\
Shrubs & 80.9 & 0.0 & 0.48 \\
Broadleaf crops & 69.0 & 1.8 & 1.65 \\
Savannas & 80.7 & 2.2 & 1.44 \\
Broadleaf forests & 21.6 & 16.7 & 3.91 \\
\hline
\end{tabular}

Performance metrics of the LAI/FPAR algorithm on MODIS data over Africa on March 25th, 2000. 
(a)

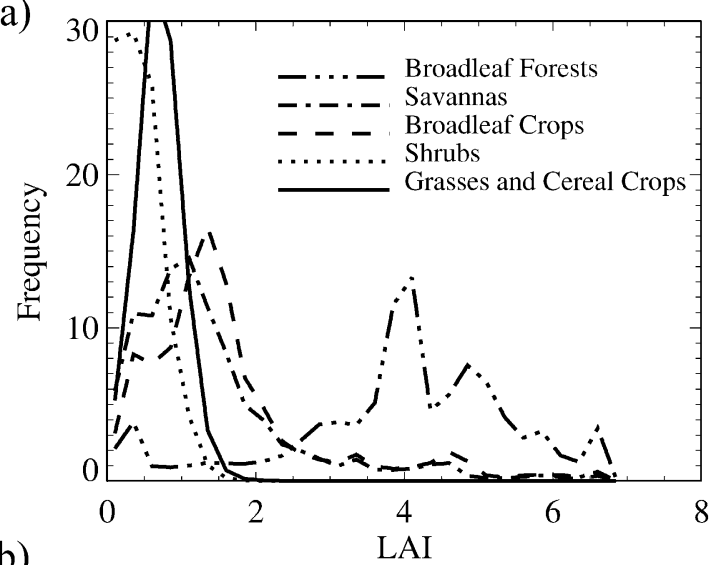

(b)

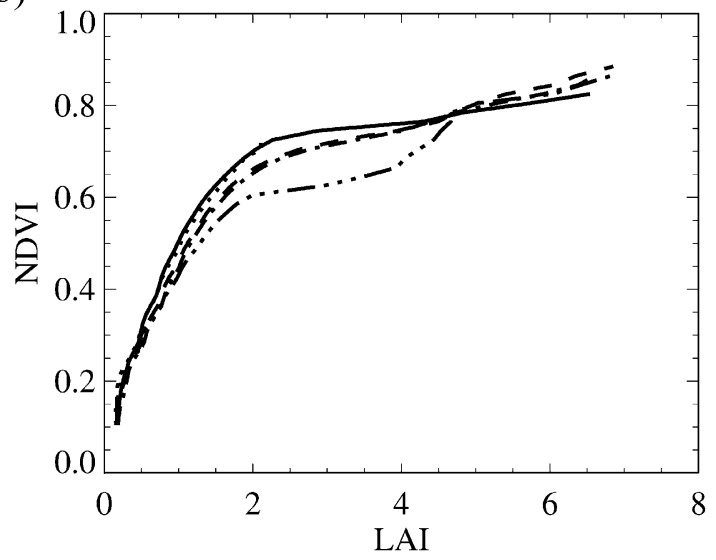

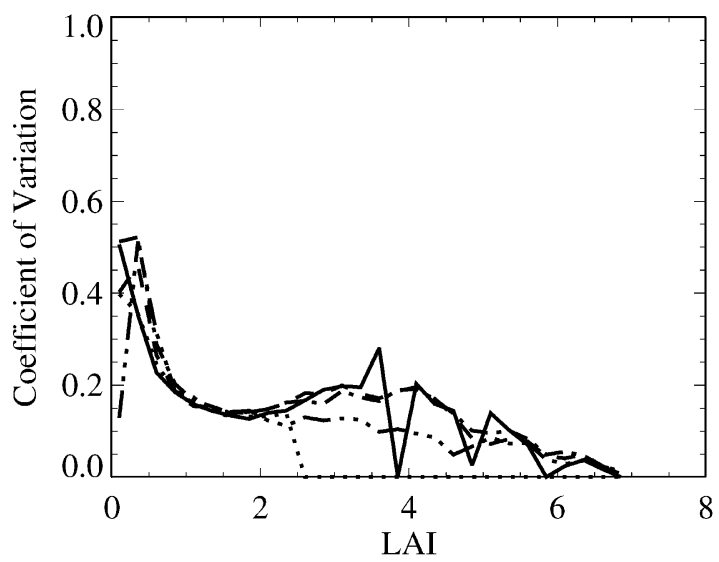

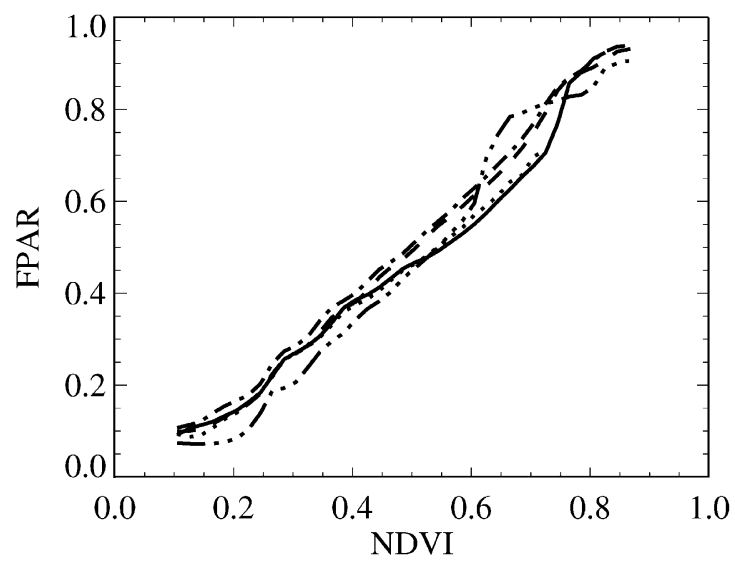

Fig. 11. (a) The distributions of retrieved LAI values and coefficient of variation (standard deviation/mean) from the main algorithm for five biomes in Africa from MODIS data on March 25th, 2000. (b) The corresponding NDVI-LAI and NDVI-FPAR relations are also shown. This relation shows that the LAI/ FPAR product follows regularities expected from physics.

the causes of variations in LAI values will be due to changes in the atmosphere. As mentioned earlier, the main algorithm fails when the pixel's reflectance data are corrupted due to clouds or atmospheric effects. NDVI, in these cases, is close to zero, therefore, the backup algorithm outputs low LAI values. Further evidence of the sensitivity of the main LUT algorithm to cloud contamination can be seen in the distribution of QA values by latitude (Fig. 10). The main algorithm fails more often over tropical latitudes where there is frequent cloud cover.

The initial performance of the main algorithm was assessed from LAI retrievals over Africa on March 25th, 2000 (Table 6 and Fig. 11). Three variables characterize the quality of LAI/FPAR retrievals - the Retrieval Index, dispersion of the solution distribution function and the rate of saturation. Good retrievals have high retrieval indices and low values of dispersion and saturation. The retrieval indices are generally high and the saturation indices are low, with the exception of broadleaf forests, because of persistent cloud cover. The biome LAI distributions and mean values are reasonable and the NDVI-LAI and NDVI-FPAR relations conform to forms expected from the physics of radiation transfer in vegetation canopies (Knyazikhin, Martonchik, Myneni, et al., 1998).

\section{Validation of the LAI/FPAR product}

\subsection{SAFARI-2000 West Season Campaign}

The responsibility for validation of the MODIS LAI/ FPAR product will be shared between the algorithm developers and validation investigators selected in response to NASA research announcements. However, for global validation, it is recognized that greater resources and coordination are required than are currently recruited. Thus, MODLAND is applying significant effort to developing community wide validation protocols and encouraging participation by data collectors and product users through the aegis of International bodies such as the working group on calibration and validation of the Committee on Earth Observation Satellites (Privette et al., 1998; Morisette et al., 2000). These activities bring together the resources of various international teams working on validation of land surface products from moderate resolution sensors.

Global validation requires field data from a range of sites representing a logical subset of the Earth's land covers. The initial focus of our validation activities is at the EOS land validation core sites as these are high priority TERRA and 
Table 7

LAI-net sites for validation of LAI/FPAR products from MODIS and other moderate resolution sensors

\begin{tabular}{|c|c|c|c|}
\hline Name & Country & Biome & $\begin{array}{l}\text { EOS } \\
\text { Core Site }\end{array}$ \\
\hline USDA BARC, MD & U.S. & broadleaf cropland & $x$ \\
\hline Bondville, IL & U.S. & broadleaf cropland & $x$ \\
\hline Gainesville, FL & U.S. & broadleaf cropland & \\
\hline Tapajos & Brazil & broadleaf Forest & $x$ \\
\hline Hawaii & U.S. & broadleaf Forest & \\
\hline Harvard Forest, MA & U.S. & broadleaf Forest & $x$ \\
\hline Park Falls, WI & U.S. & broadleaf Forest & $x$ \\
\hline Uradry & Australia & grassland & $x$ \\
\hline Osage, $\mathrm{OK}$ & U.S. & grassland & \\
\hline Konza, KS & U.S. & grassland & $\times$ \\
\hline East Anglia & England & grassland & $x$ \\
\hline Vernon, TX & U.S. & grassland & \\
\hline BOREAS NSA & Canada & needleleaf forest & $\times$ \\
\hline Cascades, OR & U.S. & needleleaf forest & $\times$ \\
\hline EMATREF & France & needleleaf forest & \\
\hline Yaqui Valley & Mexico & shrubland & \\
\hline $\begin{array}{l}\text { San Pedro Basin/ } \\
\text { SALSA, AZ }\end{array}$ & U.S. & shrubland & $x$ \\
\hline Skukuza & South Africa & shrubland/woodland & $\times$ \\
\hline $\begin{array}{l}\text { New Zealand } \\
\text { network }\end{array}$ & New Zealand & various & \\
\hline Canada Network & Canada & various & \\
\hline Mongu & Zambia & woodland & $\times$ \\
\hline Cerrado & Brazil & woodland & \\
\hline Safari-2000 & Botswana & various & \\
\hline Ruokolahti & Finland & needleleaf forest & \\
\hline Kejimkujik & Canada & broadleaf forest & \\
\hline
\end{tabular}

Landsat 7 land validation activities and product generation targets. The sites typically have a history of in-situ and remote observations and are expected to facilitate both validation and early EOS science. Centralized web based archiving of ASTER, MISR, MODIS, Landsat 7 ETM+, and IKONOS products in relatively easy-to-use formats are planned for these sites. These core sites together with several investigator volunteered sites comprise the LAInet, an informally coordinated array of sites for possible validation of LAI/FPAR products from MODIS and other moderate resolution sensors (Table 7).

We participated in the SAFARI 2000 wet season field campaign in Southern Africa from March 3 to 18, 2000. Ground measurements of LAI, FPAR, leaf and canopy hemispherical reflectance and transmittance, and directional canopy reflectance were made using the LAI-2000 plant canopy analyzer, AccuPAR ceptometer, LI-1800 portable spectroradiometer and ASD handheld spectroradiometer (no endorsements intended here and through out). LAI and FPAR were intensively measured at four different sites, Pandamatenga, Maun, Okwa and Tshane (from north to south in Botswana), where the vegetation ranged from moist closed woodland to arid sparsely shrub-covered grassland.

At each of the four sites, measurements were collected every $25 \mathrm{~m}$ along three parallel 750 -m-long east-west transects. These transects were $250 \mathrm{~m}$ apart along the north-south axis. In addition, data were also collected on a $250 \times 300 \mathrm{~m}$ grid at every $50 \mathrm{~m}$. The measured LAI distributions at the four sites are shown in Fig. 12 together with the distribution assembled from the $1 \mathrm{~km}$ MODIS LAI product over pixels in the vicinity with the same land covers. The agreement between the two is noteworthy considering high variability in both field data and the product.

The scaling problem in the validation of moderate resolution products with higher resolution satellite imagery and field measurements can be stated as follows. Scaling is defined as the process by which we establish that the LAI/ FPAR values derived from coarse resolution sensor data are the arithmetic averages of LAI/FPAR values derived inde-
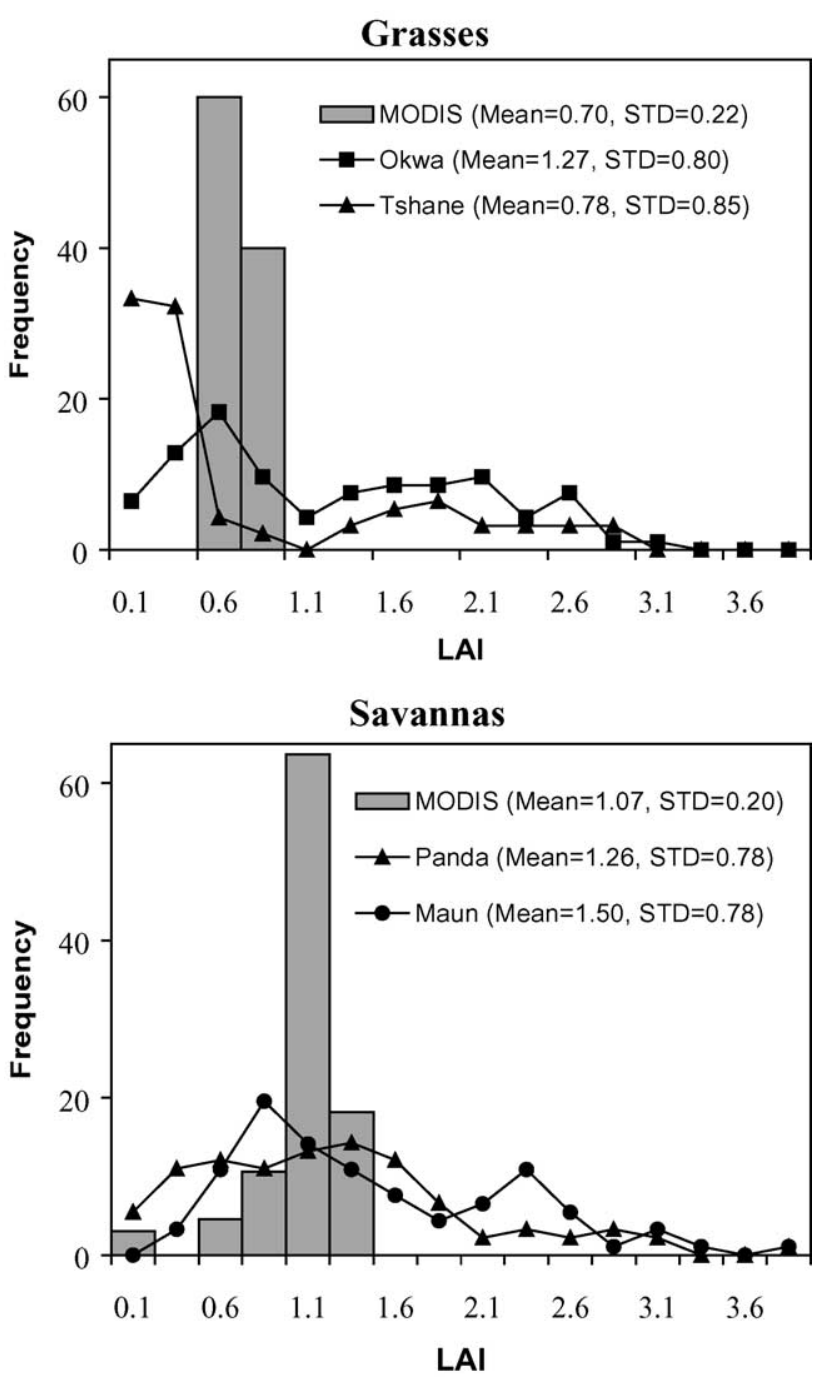

Fig. 12. Comparison of MODIS LAI product with SAFARI 2000 wet season field campaign measurements. Figures show the distribution of LAI values derived from field measurements and evaluated with the MODIS LAI/FPAR algorithm. Dispersions derived from field measurements are higher than those derived from MODIS retrievals because the MODIS LAI/ FPAR algorithm only accounts for the most probable situations encountered in reality. 
MODIS Retrievals, Apr. 3, 2000

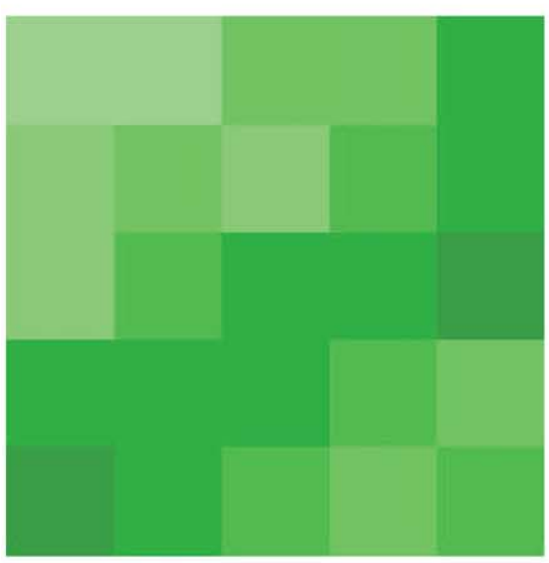

ETM Retrievals, Apr. 3, 2000
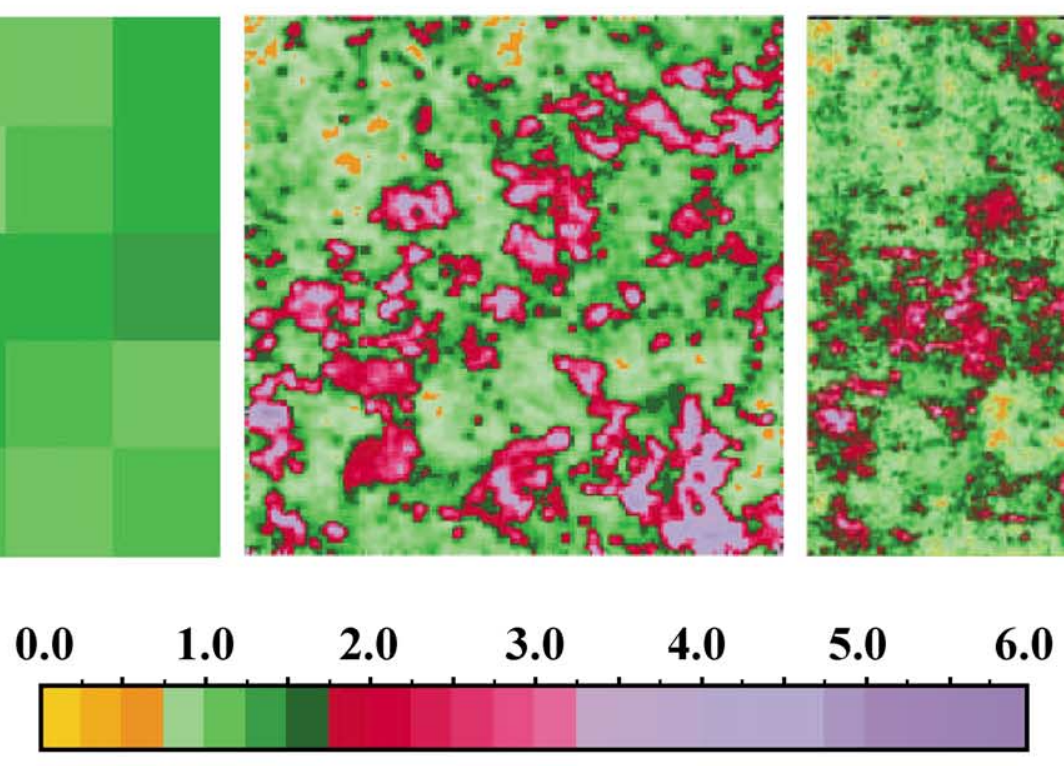

\section{Leaf Area Index}

IKONOS Retrievals,

Mar. 30, 2000

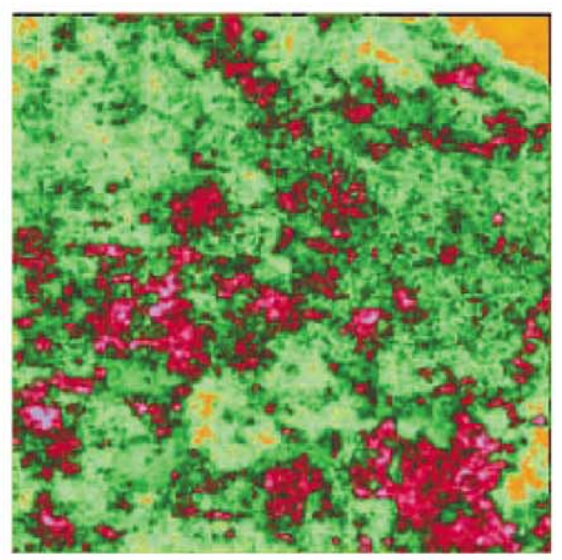

6.0

Fig. 13. Maps of LAI of a $5 \times 5 \mathrm{~km}$ region at Maun in Botswana retrieved by the LAI/FPAR algorithm with MODIS, LANDSAT ETM+ and IKONOS data. These are the temporally closest available images to the dates of the field measurements.

pendently from fine resolution sensor data over the same region (Tian et al., in press). The variables $p_{t}$ and $p_{a}$, which imbue scale dependence to the algorithm via modifications to the LUTs, can be derived from model calculations and measurements of leaf and canopy spectral properties (Panferov et al., 2001). Ground-based measurements that allow specification of $p_{t}$ and $p_{a}$ are included in a prioritized list of measurements needed for validation of MODIS LAI/FPAR product. Thus, the transect and grid point measurements collected in the field can be used to obtain the scaling parameters $p_{t}$ and $p_{a}$ at spatial resolutions of interest.

The LAI maps of a $5 \times 5 \mathrm{~km}$ region at one of the sites, Maun, derived from MODIS $(1 \mathrm{~km})$, ETM+ $(30 \mathrm{~m})$ and IKONOS (4 m) data, are shown in Fig. 13. The MODIS

\section{LAI Histogram}

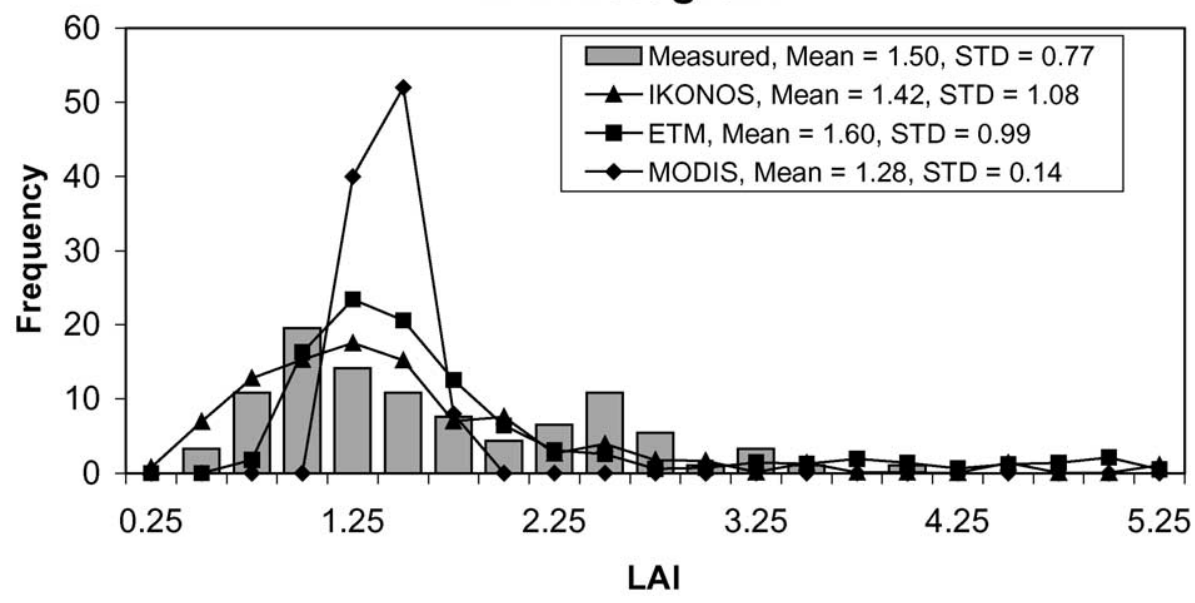

Fig. 14. Distributions of LAI retrievals shown in Fig. 13 together with field measurements at Maun, Botswana. 


\section{IKONOS Retrievals}

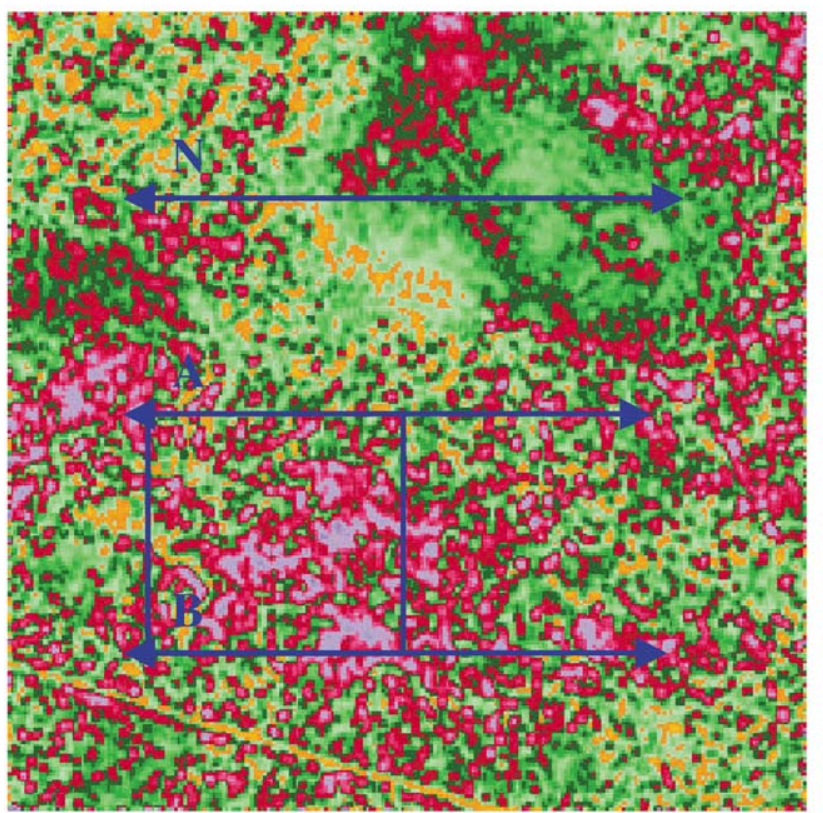

\begin{tabular}{|c|c|c|}
\hline Experiment & IKONOS LAI & $\begin{array}{c}\text { Measured } \\
\text { LAI }\end{array}$ \\
\hline Transect N & $1.47 \pm 0.732$ & $1.77 \pm 0.82$ \\
\hline Transect A & $1.69 \pm 1.31$ & $1.14 \pm 0.817$ \\
\hline Transect B & $2.31 \pm 1.57$ & $1.62 \pm 0.57$ \\
\hline Grid & $2.02 \pm 1.54$ & $1.21 \pm 0.68$ \\
\hline
\end{tabular}

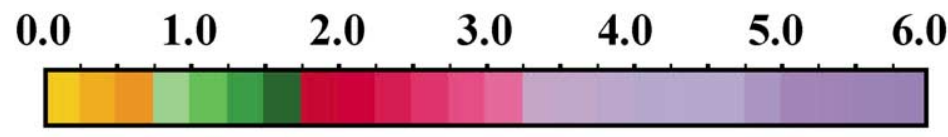

Leaf Area Index

Fig. 15. High-resolution IKONOS-based LAI retrievals compared to transect and grid field measurements at Maun, Botswana. The transect and grid measurements are explained in the text.

LAI/FPAR algorithm was used in all cases, but with lookup-tables adjusted for resolution of ETM+ and MODIS reflectance data. The retrieved distributions are shown in
Fig. 14 together with field measurements. The agreement between the various distributions illustrates the validity of the scaling approach and the MODIS LAI product for this

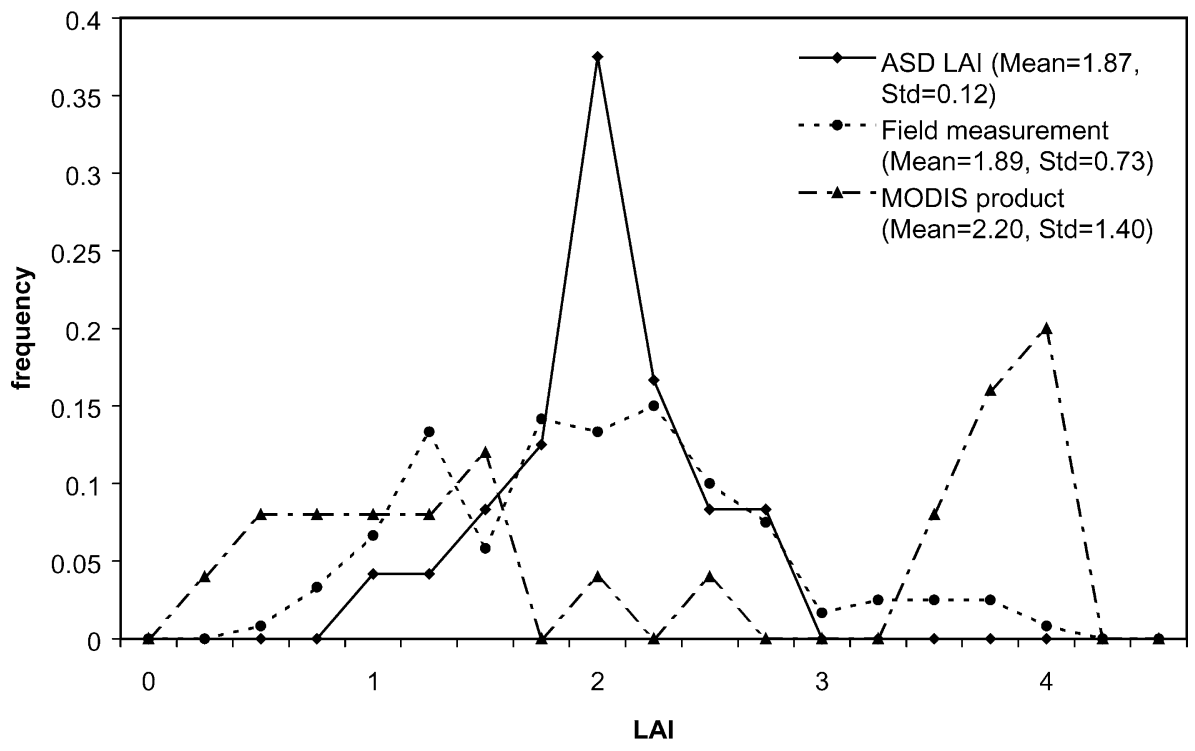

Fig. 16. Distributions of LAI retrieved from top-of-the-canopy ASD data, the MODIS product and field measurements at the Ruokolahti needle forest experimental site. ASD refers to LAI retrievals from top of the canopy reflectance measurements made with an ASD mounted on a helicopter. 
site. In Fig. 15, the higher resolution IKONOS-based LAI retrievals are compared with both the transect and the grid field measurements. Again, the agreement between the retrievals and measurements is noteworthy.

\subsection{Field campaign at Ruokolahti}

We participated in a field campaign at a needle forest site (mostly pines) near Ruokolahti $\left(61.32^{\circ} \mathrm{N}, 28.43^{\circ} \mathrm{E}\right)$ Finland from June 14 to 21 of 2000 and collected data for validation of the MODIS LAI/FPAR product. During this week, LAI, FPAR, canopy reflectance, canopy transmittance and soil reflectance were intensively measured with LAI-2000 canopy analyzers, ACCUPAR ceptometers, LI-1800 portable spectroradiometer and ASD handheld spectroradiometer. The canopy reflectances, directional and hemispherical, were measured by mounting the ASD on a helicopter. A $1 \times 1 \mathrm{~km}$ site was chosen for intensive ground sampling at a resolution of $50 \mathrm{~m}$. Based on a CCD image of the site, the canopy was stratified into three classes depending on the tree density and age. In these three classes, data were also collected at a higher resolution of $25 \mathrm{~m}$ in a plot size of $200 \times 200 \mathrm{~m}$. The LAI distribution retrieved from the topof-the-canopy helicopter ASD data and the MODIS LAI product agree well with the field data (Fig. 16).

\subsection{Other field campaigns}

We are presently analyzing data collected in 2000 at two broadleaf forest sites-Harvard Forest in Massachusetts and Kejimkujik National Forest Reserve in Nova Scotia, Canada. Field campaigns in 2001 are targeted for validation of the LAI/FPAR product in cereal and broadleaf crops, shrubs and tropical humid forests. These activities are aimed at quantifying uncertainty of the MODIS LAI/FPAR product in all the six structural biomes. Further evaluation of the product will be performed by validation investigators and the large community of users.

\section{Concluding remarks}

This paper presented an overview of research related to the MODIS LAI/FPAR algorithm and the product. Example results highlighting salient features of the algorithm and its performance were discussed to provide an understanding of the LAI/FPAR products from MODIS. The presented results indicate expected and satisfactory functionality of the algorithm in the operational mode. Initial results of validation, that is, comparison of the MODIS LAI/FPAR fields with ground measurements, are encouraging. However, in order to globally validate the product and to assess its use for scientific analyses, participation by the community-at-large is required. Therefore, the products have been released to the community as early as 5 months from the date of first light.

\section{Acknowledgements}

This research was funded by the NASA MODIS program. Several individuals not listed in the byline have contributed significantly to the MODIS LAI/FPAR research and project activities. In particular, we gratefully acknowledge the contributions of Nazmi El-Saleous, Chris Justice, David Roy and Robert Wolfe.

\section{References}

Berthelot, B., Adam, S., Kergoat, L., Cabot, F., Dedieu, G., \& Maisongrande, P. (1997). A global dataset of surface reflectances and vegetation indices derived from AVHRR/GVI time series for 1989 1990: The LAnd SUrface Reflectances (LASUR) data. Proc. Commun. 7th Int. Symp. Physical Measurements and Signatures in Remote Sens. Courchevel, France, Apr. 7-11, 1997.

Carlson, T. N., \& Ripley, D. A. (1997). On the relation between NDVI, fractional vegetation cover, and leaf area index. Remote Sens. Environ., $62,241-252$.

Deschamps, P. Y., Bréon, F. M., Leroy, M., Podaire, A., Bricaud, A., Buriez, J. C., \& Sèze, G. (1994). The POLDER mission: Instrument characteristics and scientific objectives. IEEE Trans. Geosci. Remote Sens., 32, 598-615.

Diner, D. J., Asner, G. P., Davies, R., Knyazikhin, Y., Muller, J. P., Nolin, A. W., Pinty, B., Schaaf, C. B., \& Stroeve, J. (1999). New directions in Earth observing: Scientific application of multi-angle remote sensing. Bull. Am. Meteorol. Soc., 80, 2209-2228.

Hansen, M. C., DeFries, R. S., Townshend, J. R. G., \& Sohlberg, R. (2000). Global land cover classification at $1 \mathrm{~km}$ spatial resolution using a classification tree approach. Int. J. Remote Sens., 21, 1331-1364.

Jasinski, M. F. (1996). Estimation of subpixel vegetation density of natural regions using satellite multispectral imagery. IEEE Trans. Geosci. Remote Sens., 34, 804-813.

Justice, C. O., Vermote, E., Townshend, J. R. G., Defries, R., Roy, D. P., Hall, D. K., Salomonson, V. V., Privette, J. P., Riggs, G., Strahler, A., Lucht, W., Myneni, R. B., Knyazikhin, Y., Running, S. W., Nemani, R. R., Wan, Z., Huete, A., Leeuwen, W., Wolfe, R. E., Giglio, L., Muller, J. P., Lewis, P., \& Barnsley, M. J. (1998). The moderate resolution imaging spectroradiometer (MODIS): Land remote sensing for global research. IEEE Trans. Geosci. Remote Sens., 36, 1228-1249.

Justice, C. O., Wolfe, W., El-Saleous, N., Descloitres, J., Vermote, E., Roy, D., Owens, J., \& Masuoka, E. (2000). The availability and status of MODIS Land products. Earth Obs., 12, 8-18.

Knyazikhin, Y., Glassy, J., Privette, J. L., Tian, Y., Lotsch, A., Zhang, Y., Wang, Y., Morisette, J. T., Votava, P., Myneni, R. B., Nemani, R. R., \& Running, S. W. (1999). MODIS Leaf Area Index (LAI) and Fraction of Photosynthetically Active Radiation Absorbed by Vegetation (FPAR) Product (MOD15) Algorithm, Theoretical Basis Document, NASA Goddard Space Flight Center, Greenbelt, MD 20771, USA.

Knyazikhin, Y., Martonchik, J. V., Diner, D. J., Myneni, R. B., Verstraete, M., Pinty, B., \& Gobron, N. (1998). Estimation of vegetation leaf area index and fraction of absorbed photosynthetically active radiation from atmosphere-corrected MISR data. J. Geophys. Res., 103, 32239-32256.

Knyazikhin, Y., Martonchik, J. V., Myneni, R. B., Diner, D. J., \& Running, S. W. (1998). Synergistic algorithm for estimating vegetation canopy leaf area index and fraction of absorbed photosynthetically active radiation from MODIS and MISR data. J. Geophys. Res., 103, 32257-32274.

Leroy, M., Deuze, J. L., Breon, F. M., Hautecoeur, O., Herman, M., Buriez, J. C., Tanre, D., Bouffies, S., Chazette, P., \& Roujean, J. L. (1997). Retrieval of atmospheric properties and surface bidirectional reflectances over land from POLDER/ADEOS. J. Geophys. Res., 102, $17023-17037$. 
Liu, Q., \& Huete, A. (1995). A feedback based modification of the NDVI to minimize canopy background and atmospheric noise. IEEE Trans. Geosci. Remote Sens., 33, 457-465.

Lotsch, A., Tian, Y., Friedl, M. A., \& Myneni, R. B. (2001). Land cover mapping in support of LAI and FAPAR retrievals from EOS-MODIS and MISR: Classification methods and sensitivities to errors. Int. J. Remote Sens., (in press).

Loveland, T. R., Zhu, Z., Ohlen, D. O., Brown, J. F., Redd, B. C., \& Yang, L. (2000). An analysis of the IGBP global land cover characterization process. Photogrammetric Eng. Remote Sens., 65, 1021-1031.

Morisette, J., Privette, J., Guenther, K., Belward, A., \& Justice, C. O. (2000). The CEOS Land Product Validation (LPV) Subgroup: Summary of May 23-25th Meeting. Earth Obs., 12(4), 6-9.

Myneni, R. B., Hall, F. G., Sellers, P. J., \& Marshak, A. L. (1995). The meaning of spectral vegetation indices. IEEE Trans. Geosci. Remote Sens., 33, 481-486.

Myneni, R. B., \& Ross, J. (1991). Photon-vegetation interactions: Applications in optical remote sensing and plant physiology. New York, USA: Springer-Verlag.

Panferov, O., Knyazikhin, Y., Myneni, R. B., Szarzynski, J., Engwald, S., Schnitzler, K. G., \& Gravenhorst, G. (2001). The role of canopy structure in the spectral variation of transmission and absorption of solar radiation in vegetation canopies. IEEE Trans. Geosci. Remote Sens., $39(2), 241-253$

Price, J. C. (1993). Estimating leaf area index from satellite data. Remote Sens. Environ., 31, 727-734.

Privette, J. L., Myneni, R. B., Morisette, J. T., \& Justice, C. O. (1998). Global validation of EOS LAI and FPAR products. Earth Obs., 10, 39-42.

Ross, J. (1981). The radiation regime and architecture of plant stands. The Hague, The Netherlands: Dr. W. Junk Publ.
Ross, J., Knyazikhin, Y., Marshak, A., \& Nilson, T. (1992). Mathematical modeling of the solar radiation transfer in plant canopies. St. Petersburg, Russia: Gidrometeoizdat (in Russian, with English abstract) $195 \mathrm{pp}$.

Sellers, P. J., Randall, D. A., Betts, A. K., Hall, F. G., Berry, J. A., Collatz, G. J., Denning, A. S., Mooney, H. A., Nobre, C. A., Sato, N., Field, C. B., \& Henderson-sellers, A. (1997). Modeling the exchanges of energy, water, and carbon between continents and the atmosphere. Science, 275, 502-509.

Tian, Y., Wang, Y., Zhang, Y., Knyazikhin, Y., Bogaert, J., \& Myneni, R. B. (2001). Radiative transfer based scaling of LAI retrievals from reflectance data of different resolutions. Remote Sens. Environ. (in press).

Tian, Y., Zhang, Y., Knyazikhin, Y., Myneni, R. B., Glassy, J., Dedieu, G., \& Running, S. W. (2000). Prototyping of MODIS LAI and FPAR algorithm with LASUR and LANDSAT data. IEEE Trans. Geosci. Remote Sens., 38, 2387-2401.

Vermote, E. F., El Saleous, N. Z., Justice, C. O., Kaufman, Y. J., Privette, J., Remer, L., Roger, J. C., \& Tanre, D. (1997). Atmospheric correction visible to middle infrared EOS-MODIS data over land surface, background, operational algorithm and validation. J. Geophys. Res., 102(14), 17131-17141.

Wang, Y., Tian, Y., Zhang, Y., El-Saleous, N., Knyazikhin, Y., Vermote, E., \& Myneni, R. B. (2001). Investigation of product accuracy as a function of input and model uncertainties: Case study with SeaWiFS and MODIS LAI/FPAR algorithm. Remote Sens. Environ., 78, 296-311.

Zhang, Y., Tian, Y., Knyazikhin, Y., Martonchik, J., Diner, D., Leroy, M., \& Myneni, R. B. (2000). Prototyping of MODIS LAI and FPAR algorithm with POLDER data over Africa. IEEE Trans. Geosci. Remote Sens., 38 , $2402-2418$. 